\title{
Study on the Effect of Magnetic Field on Temperature Domain During Electrolytic Processing
}

Jianli Jia ( $\square$ jl_202@xatu.edu.cn )

Xi'an Technological University

Mingzhe Wang

Xi'an Technological University

Tianci Xu

Xi'an Technological University

Haotian Pangyan

Xi'an Technological University

Xueying Zhou

Xi'an Technological University

\section{Research Article}

Keywords: magnetic field, electric field, flow field, temperature field, electrolytic processing

Posted Date: August 6th, 2021

DOI: https://doi.org/10.21203/rs.3.rs-764735/v1

License: (c) (1) This work is licensed under a Creative Commons Attribution 4.0 International License. Read Full License 


\title{
Study on the Effect of Magnetic Field on Temperature Domain
}

\section{during Electrolytic Processing}

\author{
Jianli Jia*, Mingzhe Wang, Tianci Xu, Haotian Pangyan, Xueying zhou \\ *School of Mechatronic Engineering, Xi'an Technological University, Xi'an 710021, \\ P.R. China
}

*Corresponding author: Jianli Jia

E-mail address: j1_202@xatu.edu.cn

Abstract: A physical model, mathematical model and geometric model of multi-physical field (electric field, flow field, temperature field, magnetic field) were established to explore the influence of magnetic field on the temperature domain in the gap during ECM. The change law of temperature domain of ECM gap under different magnetic field design methods was studied by using COMSOL MULTIPHYSICS. The scheme is as follows: the magnetic field line is perpendicular to the electric field and the flow field is parallel; the magnetic field line is parallel to the electric field and the flow field is vertical; the electric field of the magnetic field is vertical and the flow field is vertical. The change law of the influence of the magnetic field on the electrolyte temperature is studied by simulation. The changes of current density under three magnetic field design methods and different electrolyte flow were studied. The simulation results show that when the magnetic field is perpendicular to the electric field and the flow field, the temperature change is relatively gentle, and the flow field changes uniformly under the action of the magnetic field volume force, so that the change of current density is relatively stable; The current density of anodic dissolution increases with the increase of voltage, resulting in the increase of electrolyte temperature and heat, further reducing the gap and machining gap, and the temperature in the gap will be greatly increased. Under the action of magnetic field, the electrolyte flow rate increases and the electrolyte temperature decreases greatly.

Keywords: magnetic field; electric field; flow field; temperature field; electrolytic processing

\section{Declarations}

Funding: This study has been supported by the Key R\&D Project of Shaanxi Provincial Department of Science and Technology (2019GY-126), Shaanxi Province Special Processing Key Laboratory Open Fund Project (SXTZKFJJ202001), and Key R\&D Project of Shaanxi Provincial Department of Science and Technology (2019GY-112).

Conflicts of interest: We declare that we have no conflict of interest.

Availability of data and material: The data used to support the findings of this study are available from the corresponding author upon request. 
Authors' contributions: Jianli Jia: conceptualization, investigation, methodology, writing-original draft. Mingzhe Wang: software, validation. Tianci Xu: data curation, visualization. Haotian Pangyan: data curation, visualization. Xueying Zhou: article typesetting and format modification.

Ethics approval: Because the research of this paper belongs to the field of electrochemical machining, the research content of this paper does not involve ethical issues.

Consent to participate: All authors agree to participate in this manuscript.

Consent for publication: All authors agree to submit and publish this manuscript in The International Journal of Advanced Manufacturing Technology as a full-length article. 


\section{Introduction}

Electrochemical machining (ECM) is a special machining method that uses the principle of anodic dissolution of metal in electrolyte to process and shape the workpiece, electrochemical machining is widely used in aerospace, mining, military manufacturing and so on [1-5]. It involves many physical fields, such as electric field, flow field and temperature field. It is a typical multi-field coupling process, which makes it difficult to predict the electrochemical process accurately and the tool cathode cannot be designed accurately [6-8]. Therefore, in order to obtain the processing parameters that meet the requirements, a large number of process experiments are needed, which leads to the longer preparation period and higher cost of electrochemical processing, which is not easy to popularize the application of electrochemical processing [9-11]. In view of this problem, many scholars at home and abroad have carried out a lot of research on the simulation of electrochemical machining[12-15]. The simulation theory model has developed from the initial pure electric field simulation to the multi-field coupling simulation of the flow field and the temperature field [16-27]. However, the multi-field coupling simulation of adding magnetic field in the gap of electrolytic machining is rarely involved.

This paper mainly studies the distribution and variation of temperature domain in machining gap under the assistance of magnetic field. Through the study of magnetic field and temperature field, a coupling model is established to analyze the relationship between temperature field, magnetic field, electric field and flow field in electrolytic machining gap. In order to accurately realize the parameter dependence of simulation in electrolytic machining process and the final prediction of anode surface, the precision of electrolytic machining is further improved and the test period is shortened.

\section{Theoretical model:}

The multi-physical field coupling of electrolytic processing is relatively complicated, so it is difficult to study its relationship. According to the research content and purpose of this paper, the overall technical route planning is carried out, as shown in figure 1. 


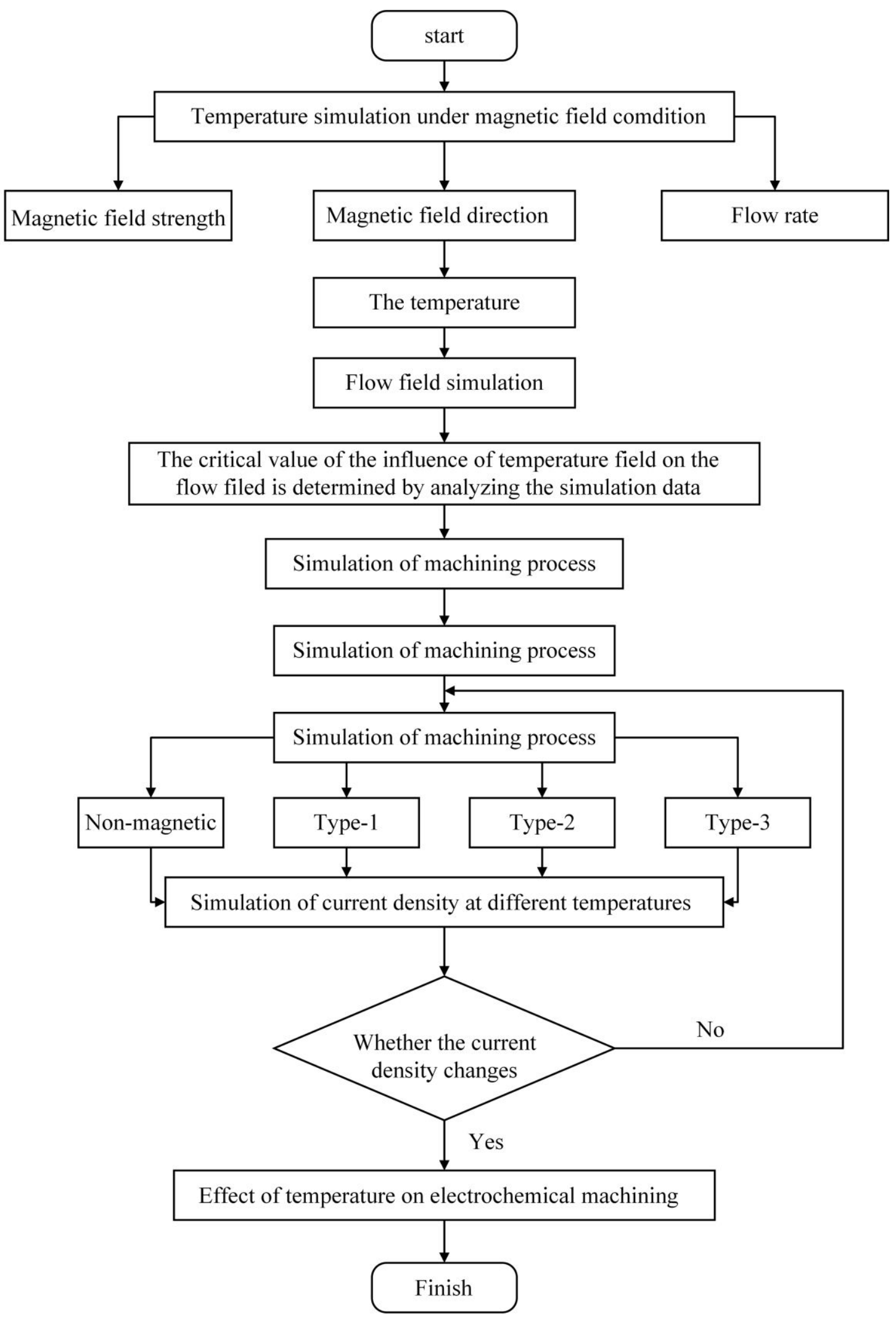

Fig. 1 Overall technical programme

To study the distribution of temperature domain under magnetic field assisted electrolysis, the anode and cathode were simplified into two plates, the anode was aluminum plate with $20 \mathrm{~mm}$, wide $10 \mathrm{~mm}$, high $3 \mathrm{~mm}$, and the cathode was copper 
plate with length 20 , width $10 \mathrm{~mm}$, high $3 \mathrm{~mm}$, as shown in figure 2 .Three different ways of adding external magnetic field are set up respectively: perpendicular to the electric field line and parallel to the flow field line; the magnetic field line is perpendicular to the flow field line but parallel to the electric field line; The magnetic field line is perpendicular to the electric field and the flow field line, as shown in figure 3.The magnetic source is a permanent magnet with coercive force of $992 \mathrm{kA} / \mathrm{m}$, the magnetic induction intensity is $0.5 \mathrm{~T}$, the gap is $0.5 \mathrm{~mm}$, and the outside is air.

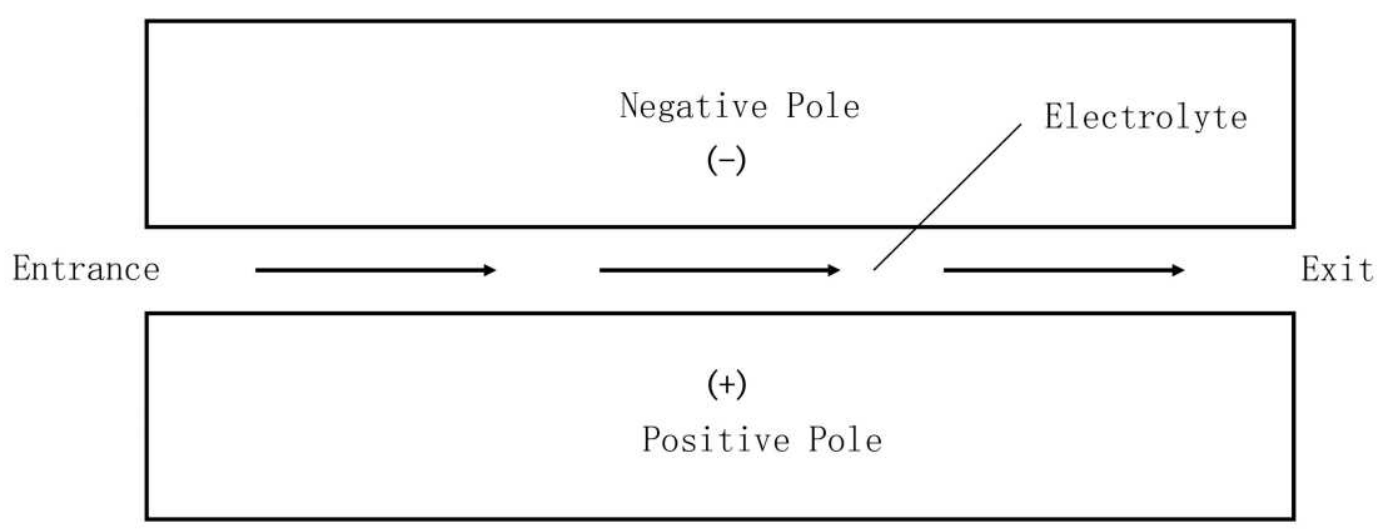

Fig. 2 Yin-Yang Polar Model

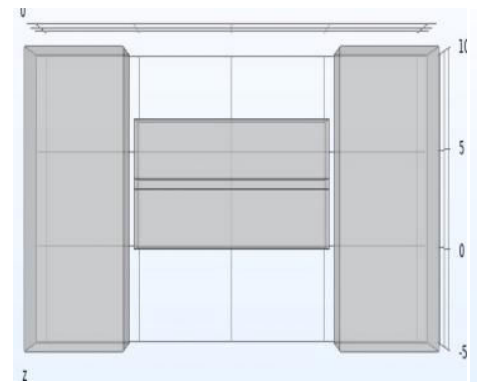

(a) Perpendicular to the electric field line and parallel to the flow field line

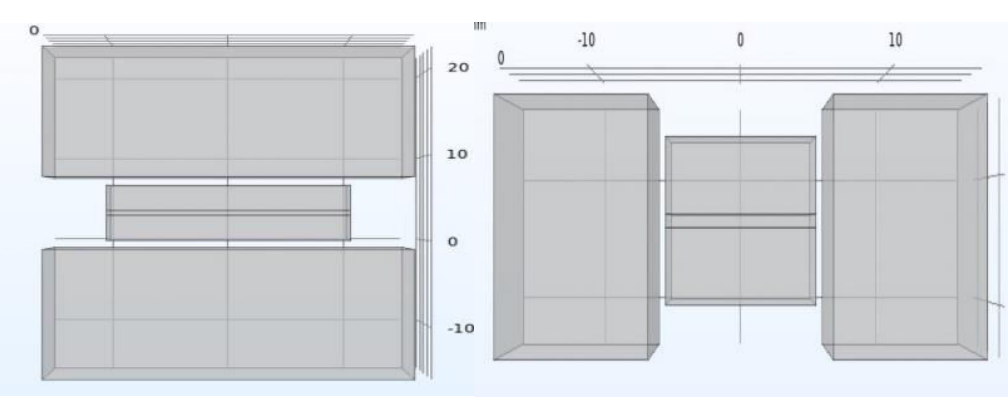

(b) The magnetic field line (c) The magnetic field line is is perpendicular to the perpendicular to the electric flow field line but parallel field and the flow field line to the electric field line

Fig. 3 Three different ways of adding external magnetic fields

\subsection{Physical model}

\section{1) Magnetic Field Model}

At present, the following two laws are usually observed in the design of magnetic field: Kirchhoff's first law and Kirchhoff's second law.

\section{2) Electric Field Model}

$$
\begin{aligned}
& \nabla^{2} \phi=0 \\
& \nabla^{2} \mathrm{U}=0
\end{aligned}
$$

If the cathode and anode surfaces are all equipotential surfaces and the electrode boundary effect is neglected, the electric potential $U$ satisfied in the electrolyte 
according to the conservation of charge.

$$
\nabla \cdot(k \nabla \mathrm{U})=0
$$
model.

Electrolyte conductivity can be defined by a temperature-dependent linear

$$
k=k_{0}\left[1+\gamma\left(\theta-\theta_{0}\right)\right]
$$

$\theta_{0}$ : initial temperature, $\theta$ : current temperature, $\mathrm{k}_{0}$ : initial conductivity, $\gamma$ : the temperature correlation coefficient.

\section{(3) Flow field model}

In order to simplify the calculation, the following assumptions are made for the fluid in modeling:

(1) The liquid is an incompressible Newtonian fluid,

(2) Since the distribution of cathode flow field in different shapes is studied, the liquid is assumed to be steady and steady flow, regardless of the energy loss of the interface, and the physical quantities are independent of time.

For incompressible viscous fluids: according to the law of conservation of mass and momentum, the Navier-Stokes equation can be satisfied:

$$
\rho(u \cdot \nabla) u=\nabla \cdot\left[-P i+\left(\mu+\mu_{T}\right)\left(\nabla_{u}+\left(\nabla_{u}\right)^{T}\right)-\frac{2}{3}\left(\mu+\mu_{T}\right)(\nabla \cdot u) i-\frac{2}{3} \rho K_{1}\right]+\rho g
$$

Meet the continuity equation:

$$
\nabla(\rho u)=0
$$

$\rho$ : fluid density $(\mathrm{g} / \mathrm{cm}), \mathrm{P}$ : pressure $(\mathrm{MPa})$ on a fluid microelement, $\mathrm{U}$ : velocity $(\mathrm{m} / \mathrm{s})$ in the direction of feed, $\mu_{T}$ : dynamic viscosity, $\mathrm{g}$ : acceleration of gravity, $\nabla$ : gradient operator.

$\mathrm{k}-\varepsilon$ In this paper, the standard model is used to solve the problem. For the steady flow of incompressible fluid, the transport equations corresponding to the turbulent kinetic energy $\mathrm{k}$ and dissipation rate are as follows:

$$
\begin{gathered}
\frac{\partial(\rho K)}{\partial t}+\frac{\partial\left(\rho K u_{i}\right)}{\partial x_{i}}=\frac{\partial}{\partial x_{j}}\left[\left(\mu+\frac{\mu_{i}}{\sigma_{k}}\right) \frac{\partial K}{\partial x_{j}}\right]+G_{K}-\rho \varepsilon \\
\frac{\partial(\rho \varepsilon)}{\partial t}+\frac{\partial\left(\rho \varepsilon u_{i}\right)}{\partial x_{j}}=\frac{\partial}{\partial x_{j}}\left[\left(\mu+\frac{\mu_{i}}{\sigma \varepsilon}\right) \frac{\partial \varepsilon}{\partial x_{j}}\right]+\frac{C_{c 1}}{K} G_{k}-C_{C 2} \rho \frac{\varepsilon^{2}}{k} \\
G_{K}=\rho C_{\mu} \frac{K^{2}}{\varepsilon}\left(\frac{\partial \mu_{i}}{\partial x_{j}}+\frac{\partial \mu_{j}}{\partial x_{j}}\right) \frac{\partial \mu_{i}}{\partial x_{i}}
\end{gathered}
$$

$u_{i}$ : turbulent viscosity, $\varepsilon$ : turbulent dissipation rate, k: turbulent kinetic energy, turbulent viscosity, $P_{k}$ :turbulent kinetic energy production term caused by mean velocity gradient, $\mathrm{G}_{k}$ : generation term of the end kinetic energy $\mathrm{k}$ caused by the average velocity gradient; The model constants $C_{\varepsilon 1}, C_{\varepsilon 2}, C_{\mu}, \sigma_{k}, \sigma_{\varepsilon}$ are taken as 
$0.09,1.44,1.92,1.0,1.3$ respectively.

\section{4) Heat Transfer Model}

The temperature distribution of electrolyte in the machining gap can be described by convection-diffusion equation:

$$
\rho C_{p} \frac{\partial \theta}{\partial t}+\rho C_{p} v \cdot \nabla \theta=\nabla \cdot\left(\mathrm{k}_{t} \nabla \theta+Q_{b u l k}\right)
$$

$\mathrm{C}_{\mathrm{p}}$ : constant pressure heat capacity of electrolyte mass, $k_{t}$ :thermal conductivity of electrolyte, $Q_{b u l k}$ :heat produced in processing.

Ignoring the effect of reaction heat, Ohm's law shows that:

$$
Q_{\text {bulk }}=Q_{\text {Joule }}=i \cdot \nabla U
$$

$\mathrm{Q}_{\text {Joule }}$ : electrolyte coke heat, i: current density.

\subsection{Finite element model}

Three models of magnetic field placement and three-dimensional model without magnetic field are established respectively, and the distribution of temperature domain under different inlet velocity is carried out to find the critical value of flow field, and to find the range of temperature domain under different magnetic field addition mode. The technical route is shown in figure 4:

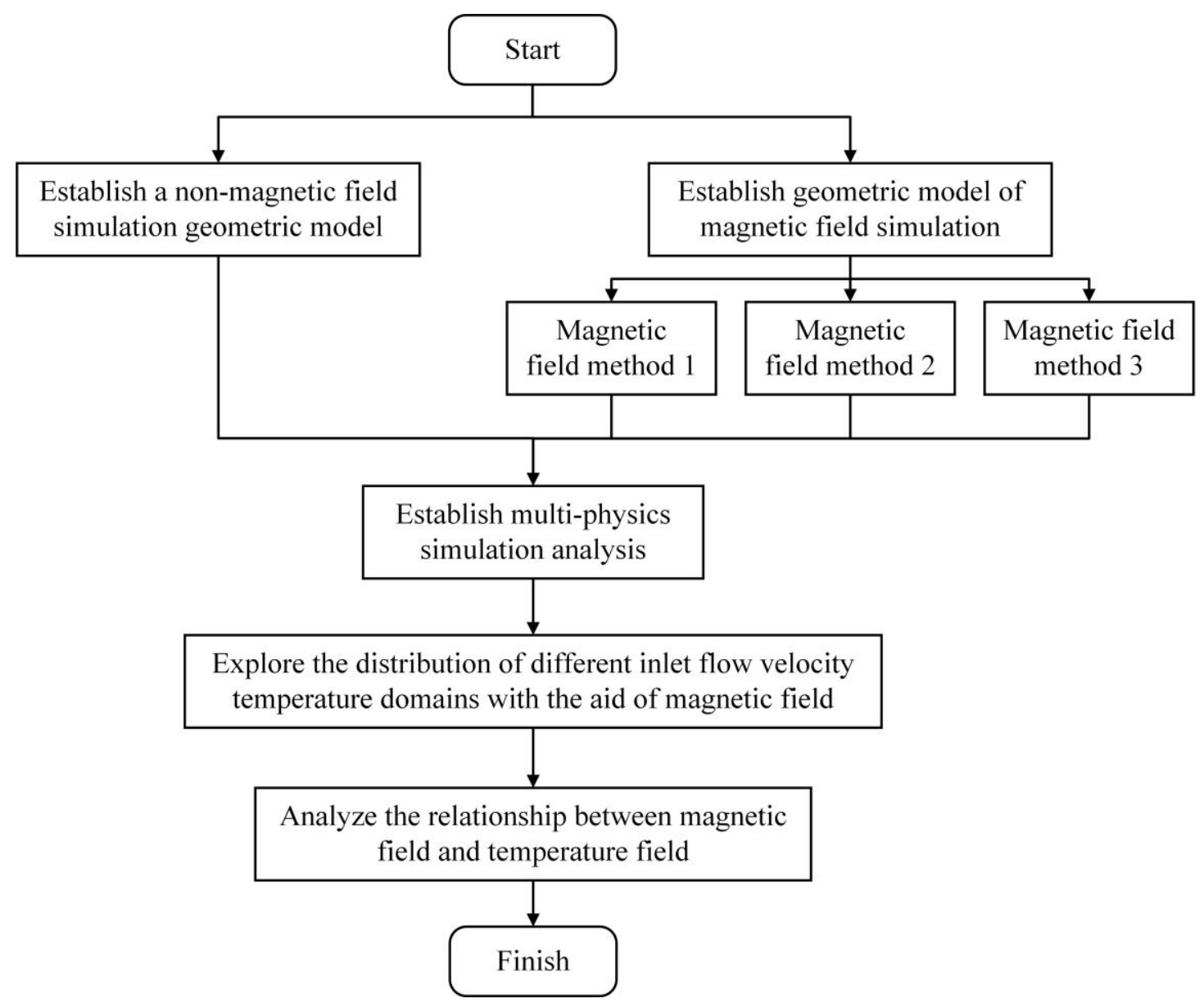

Fig. 4 Flowchart of Simulation Analysis 


\subsubsection{Material selection}

The magnetic source is $\mathrm{NdFeB}$ (permeability 1.3). The cathode is H62 brass (permeability 0.999). Anode selected as superhard aluminum LC4 (permeability 1.0). The electrolyte is $10 \%$ sodium nitrate solution (permeability 0.28 ), and at a temperature of $20^{\circ} \mathrm{C}$, the material properties of the electrolyte are shown in Table 1:

Table $1120^{\circ} \mathrm{C}$ Material properties of electrolyte

\begin{tabular}{cccc}
\hline material & Material properties & Physical symbol & Numerical(unit) \\
\hline & Electrolyte concentration & $\mathrm{w}$ & $10 \%$ \\
Electrolyte & Electrolyte density & $\rho \mathrm{E}$ & $1221 \mathrm{~kg} / \mathrm{m}^{3}$ \\
$($ NaNO3) & Dynamic viscosity of electrolyte & $\mu \mathrm{E}$ & $1.607 \mathrm{e}^{-3} \mathrm{~Pa} \cdot \mathrm{s}$ \\
& Electrolyte conductivity & $k^{\prime} \mathrm{E}$ & $7.9 \mathrm{~S} / \mathrm{m}$ \\
\hline
\end{tabular}

\subsubsection{Boundary conditions:}

1) Magnetic field boundary conditions

Add magnetization in one direction to the permanent magnet, add air range to the calculation of electromagnetic field, add a sphere to the magnetic field range, and set infinite element domain.

2) Heat transfer field

Set the heat outflow at the outlet and insulator, and the gap is set to the reaction zone for multi-physical field coupling.

3) Electric field

Cathode grounding, anode voltage of $10 \mathrm{~V}$, the insulation condition sets the surrounding gap.

4) Flow boundary conditions

Machining clearance is $0.5 \mathrm{~mm}$, the left part of the machining clearance is set to inlet velocity and the right is set to outlet pressure.

Simulation Analysis of the Influence of Magnetic Field on Temperature Field in Electrolytic Machining Gap

2.1 Temperature domain distribution and flow field distribution in machining gap without magnetic field

Distribution of temperature domain

1) Different velocity

The physical field model without magnetic field is shown in Figure 5.

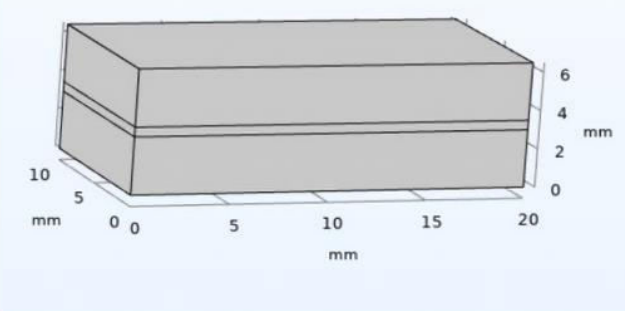

Fig. 5 3D model without magnetic field 
Because the increase of flow rate in electrolytic processing will take away the products in the gap and the heat generated, the influence of different flow rates on the temperature domain is simulated and simulated. From $0 \mathrm{~m} / \mathrm{s}$, the temperature domain changes are analyzed, as shown in figure 6 below:

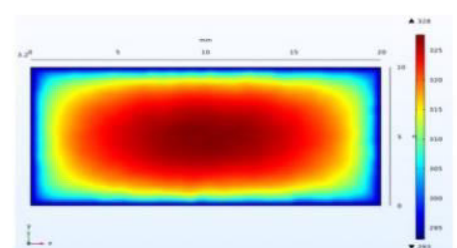

(a) $v=0 \mathrm{~m} / \mathrm{s}$

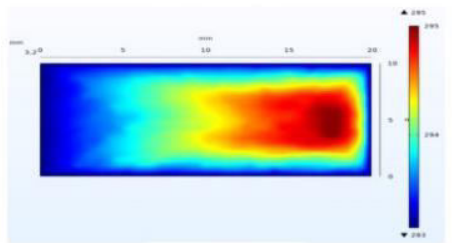

(c) $v=10 \mathrm{~m} / \mathrm{s}$

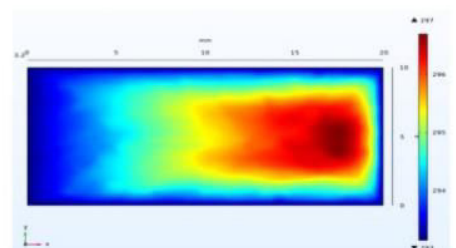

(b) $v=5 \mathrm{~m} / \mathrm{s}$

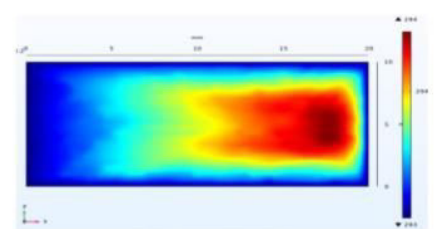

(d) $v=15 \mathrm{~m} / \mathrm{s}$

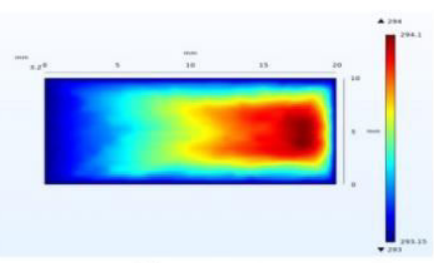

(e) $v=20 \mathrm{~m} / \mathrm{s}$

Fig. 6 Distribution of temperature domain at different flow rates without magnetic field

As shown in Figure 6, if the electrolyte flow rate is $0 \mathrm{~m} / \mathrm{s}$, without taking the heat from the gap, the temperature distribution is more uniform, a maximum of about $55^{\circ} \mathrm{C}$. When the flow rate of the electrolyte increases from $5 \mathrm{~m} / \mathrm{s}$ to $20 \mathrm{~m} / \mathrm{s}$, as the electrolyte flows, the temperature drops significantly. When the temperature is $5 \mathrm{~m} / \mathrm{s}$, the maximum temperature is about $24^{\circ} \mathrm{C}$, when the flow rate is $15 \mathrm{~m} / \mathrm{s}$, the temperature range reaches $21^{\circ} \mathrm{C}$, as the velocity continues to increase to $20 \mathrm{~m} / \mathrm{s}$, the temperature in the machining gap does not change. So when no magnetic field is added, electrolyte flow rate $15 \mathrm{~m} / \mathrm{s}$, the temperature range reaches a constant temperature state.

\section{2) Flow Field Distribution map}

Figure 7 below shows the flow field distribution in the constant temperature state in the gap between the static liquid and the flow rate of $15 \mathrm{~m} / \mathrm{s}$ without magnetic field.

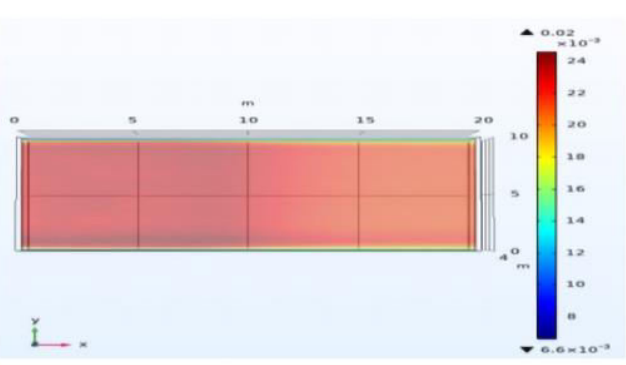

(a) $v=0 \mathrm{~m} / \mathrm{s}$

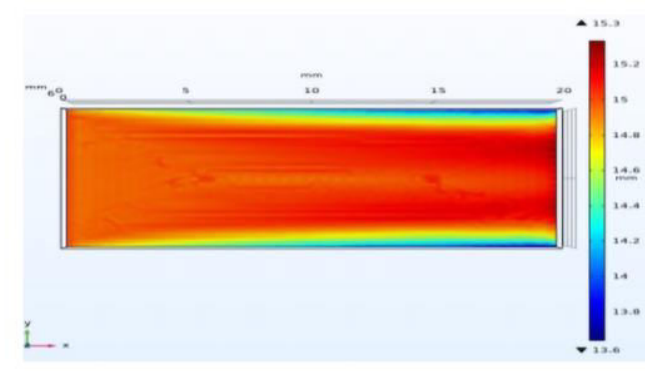

(b) $v=15 \mathrm{~m} / \mathrm{s}$

Fig. 7 Flow field distribution without magnetic field

2.2 The magnetic field is added and the magnetic field line is perpendicular to the electric field and parallel to the flow field line

1) Distribution of temperature domain at different flow rates. 
The model of perpendicular to the electric field line and parallel to the flow field line is shown in Figure 8. The magnetic field distribution is shown in Figure 9.

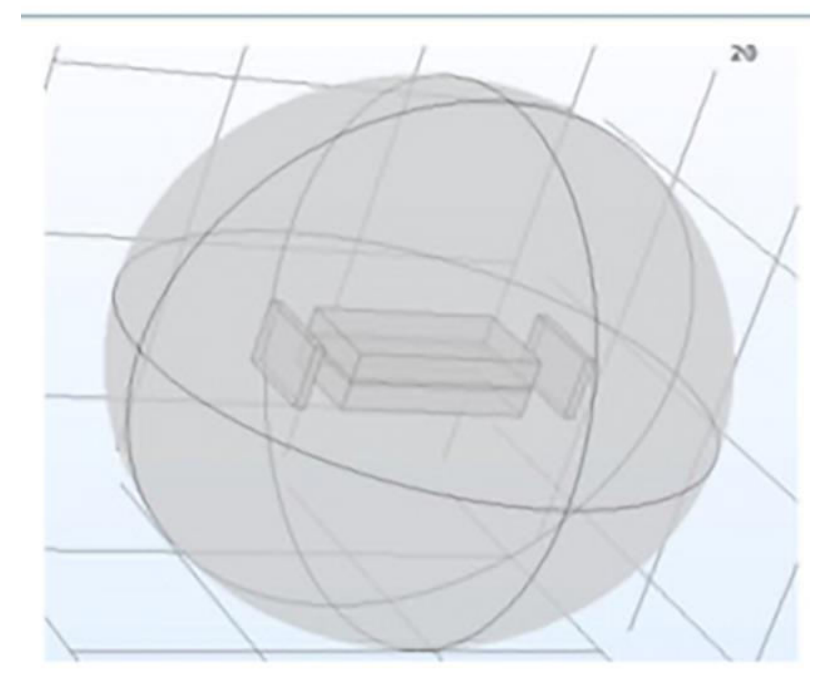

Fig. 8 3D model in comsol software

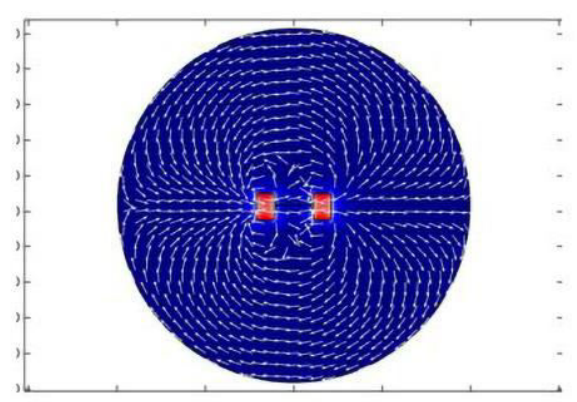

(a) Two-dimensional Distribution

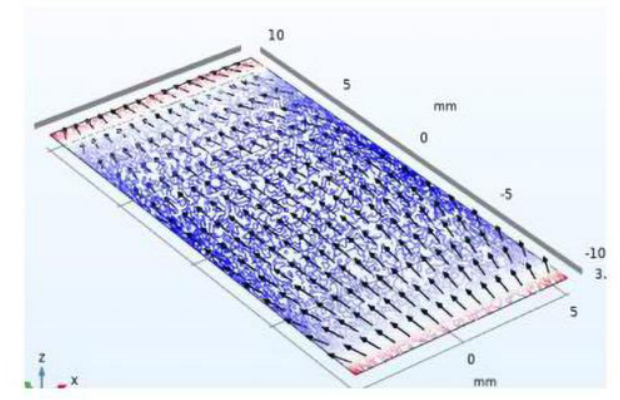

(b) Three-dimensional Distribution

Fig. 9 Distribution of magnetic field

After adding magnetic field to the turbulence model, the simulation model of temperature domain at different velocity is carried out. The final simulation results are shown in figure 10 . 


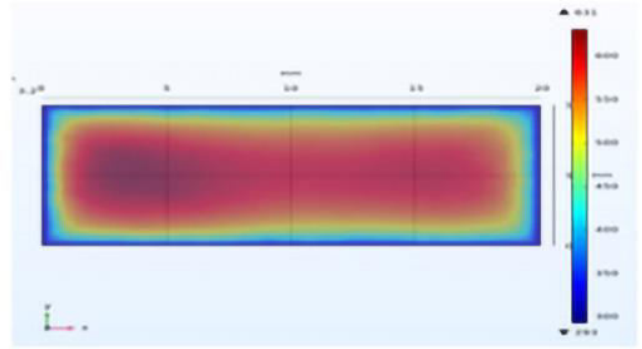

(a) $v=0 \mathrm{~m} / \mathrm{s}$

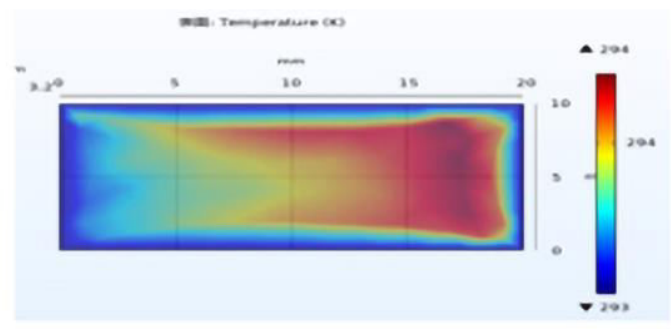

(c) $v=40 \mathrm{~m} / \mathrm{s}$

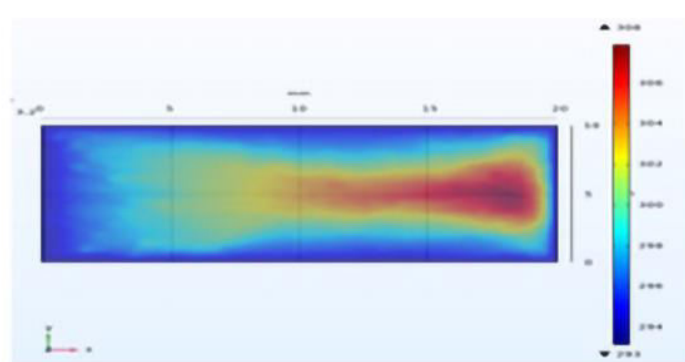

(b) $v=15 \mathrm{~m} / \mathrm{s}$

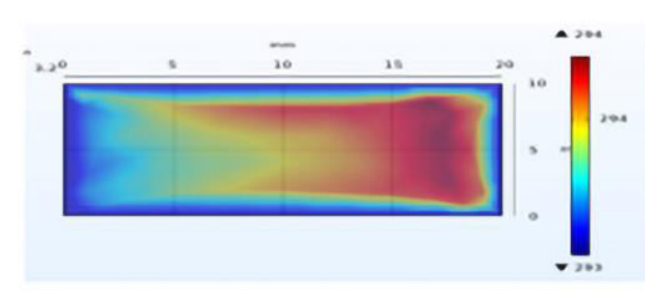

(d) $v=50 \mathrm{~m} / \mathrm{s}$

Fig. 10 Distribution of temperature regions at different flow rates

As shown in figure 10 above, without any cooling system, the temperature increases sharply to $358^{\circ} \mathrm{C}$ after adding magnetic field. The flow field is added to the diagram, the electrolyte takes away the heat in the gap and the temperature decreases rapidly. Compared with the temperature domain without magnetic field (figure 6), the maximum value of the temperature domain is $35^{\circ} \mathrm{C}$, when the flow rate is $15 \mathrm{~m} / \mathrm{s}$ and does not reach constant temperature, until the flow rate increases to $40 \mathrm{~m} / \mathrm{s}$, the temperature in the machining gap does not reach constant temperature.

\section{2) Flow Field Distribution map}

The distribution of the flow field at different flow rates after the magnetic field is added and the magnetic field line is perpendicular to the electric field and parallel to the flow field line.

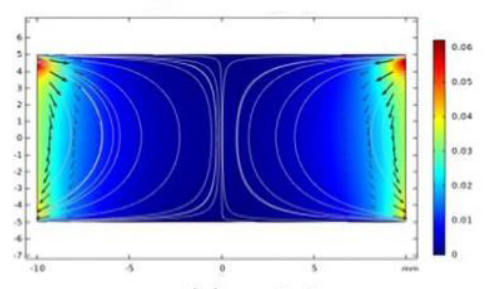

(a) $v=0 \mathrm{~m} / \mathrm{s}$

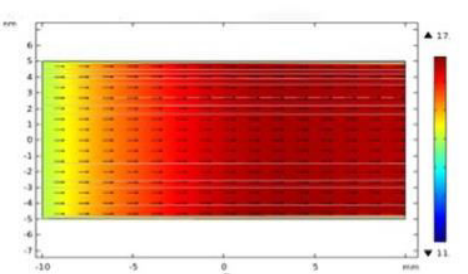

(b) $v=15 \mathrm{~m} / \mathrm{s}$

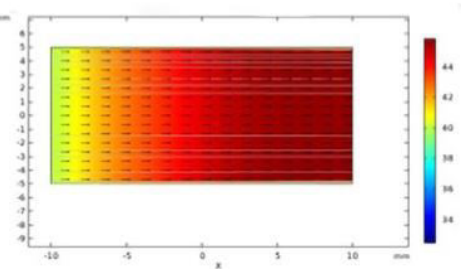

(c) $v=40 \mathrm{~m} / \mathrm{s}$

Fig. 11 Flow field distribution in gap at different inlet velocity

From figure 11 above, we can see that when the magnetic field is added, the magnetic field lines and the flow field lines are parallel to each other in static liquid, so the magnetic field has a relative promoting effect on the flow field. Under the promotion of magnetic force, the flow rate of static fluid can reach $0.06 \mathrm{~m} / \mathrm{s}$, permanent magnet is placed on the left and right sides of workpiece. When the flow 
rate of electrolyte is $15 \mathrm{~m} /$, it increases to $17.9 \mathrm{~m} / \mathrm{s}$; and the relative maximum flow rate is $44 \mathrm{~m} / \mathrm{s}$, when the flow rate of electrolyte increases to $40 \mathrm{~m} / \mathrm{s}$.

3) Compare the temperature field at relative speed when there is no magnetic field magnetic field

When the magnetic field line is perpendicular to the electric field line and the flow field line is parallel, the initial temperature increases obviously, and the temperature decreases greatly with the increase of the flow rate, as shown in figure 12.

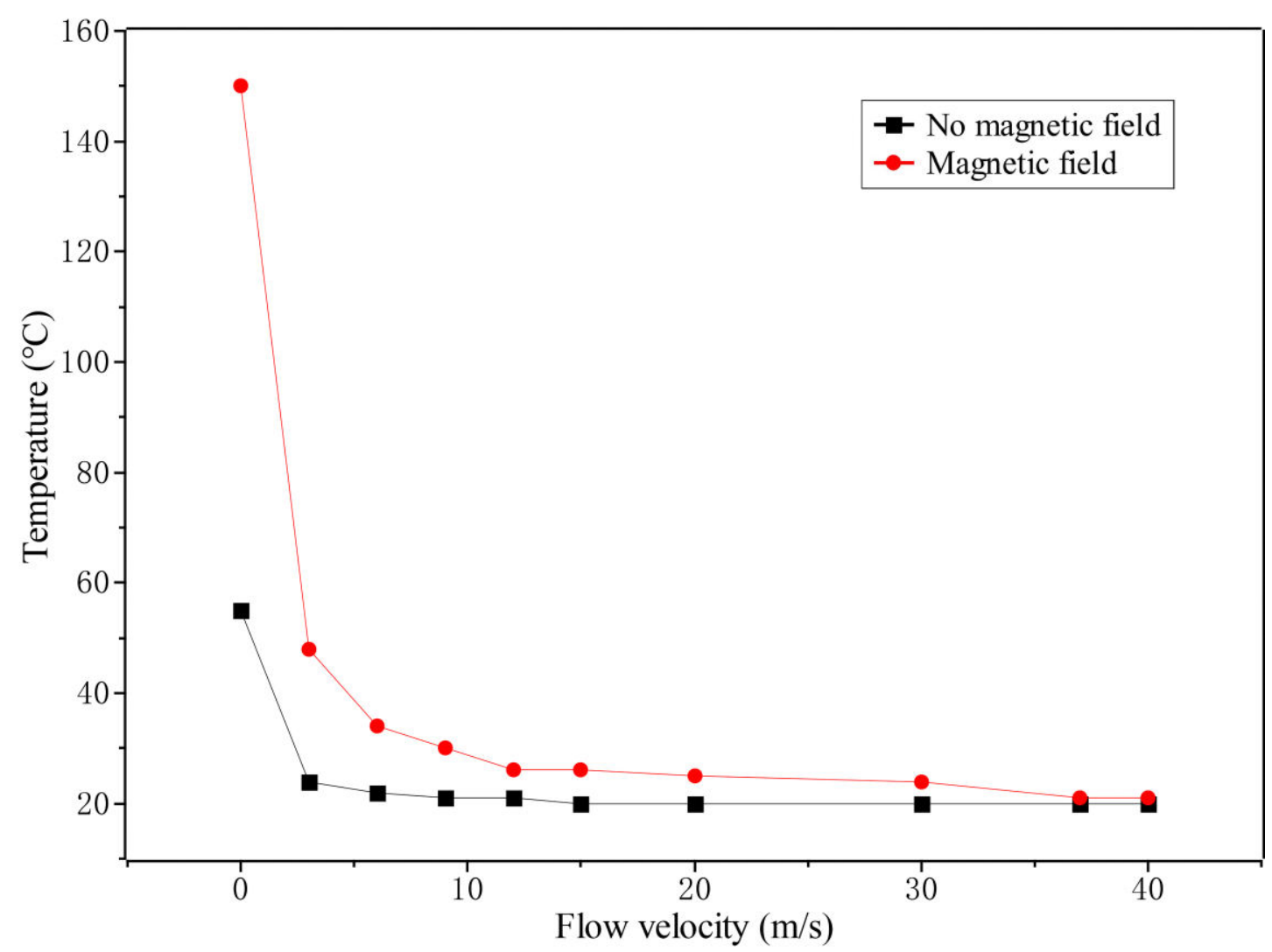

Fig. 12 Comparison of temperature at different flow rates when adding magnetic field and not adding magnetic field

2.3 The magnetic field is added and the magnetic field line is parallel to the electric field and the flow field line is perpendicular

1) Distribution of temperature domain at different velocity of flow

The model with the magnetic field line perpendicular to the flow field line but parallel to the electric field line is shown in Figure 13. The magnetic field distribution is shown in Figure 14. 


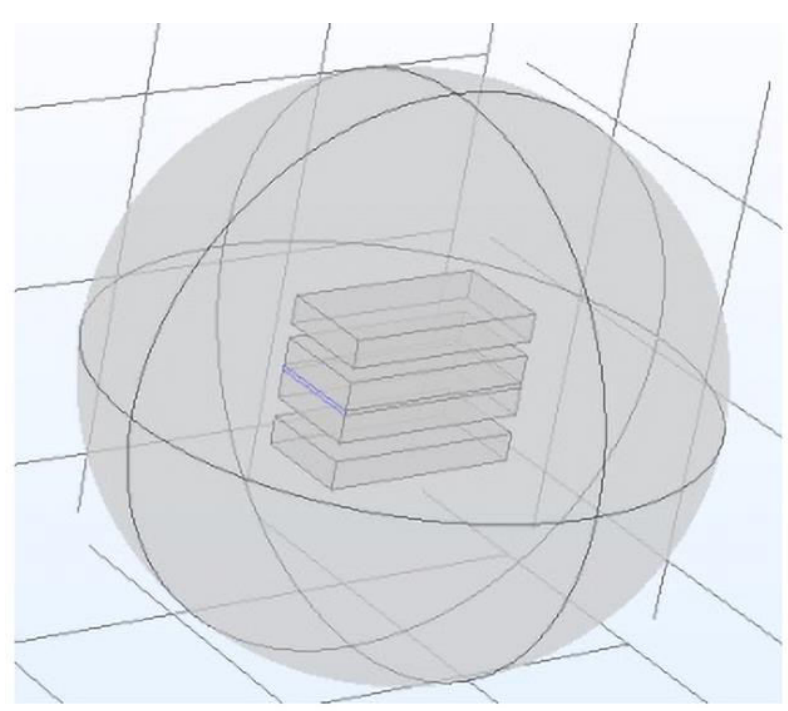

Fig. 13 3D model in Comsol software

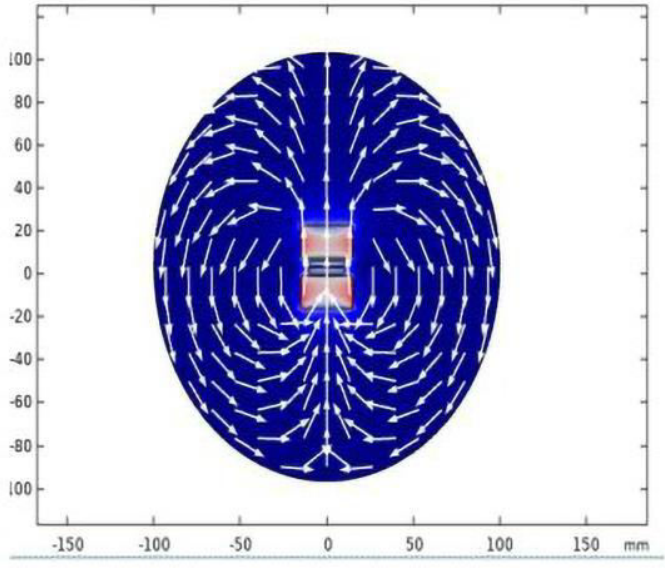

(a) Two-dimensional Model

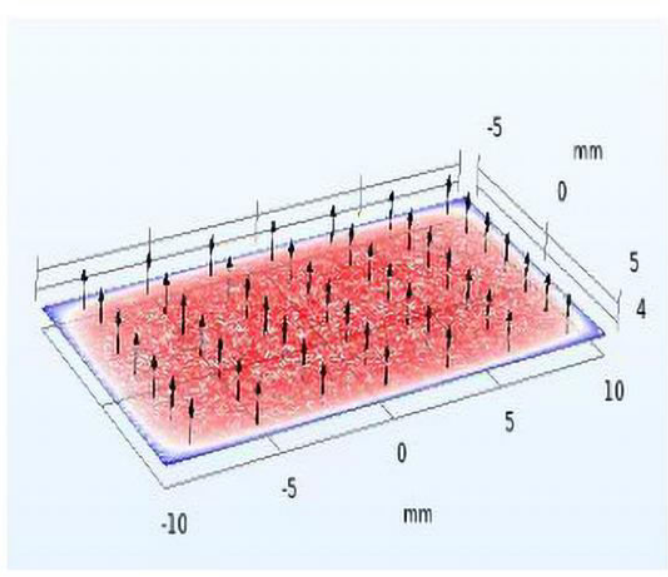

(b)Three-dimensional Model

Fig. 14 Magnetic field distribution

After adding magnetic field to the turbulence model, the simulation model of temperature domain at different velocity is carried out. The final simulation results are shown in figure 15. 


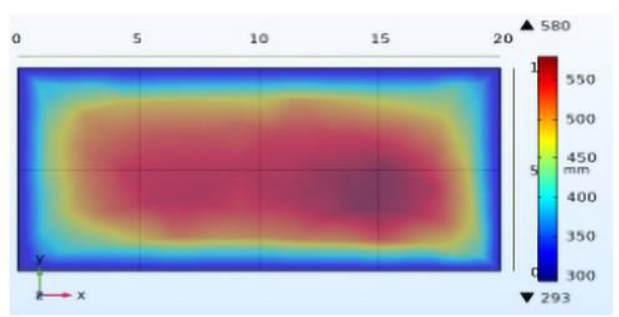

(a) $v=0 \mathrm{~m} / \mathrm{s}$

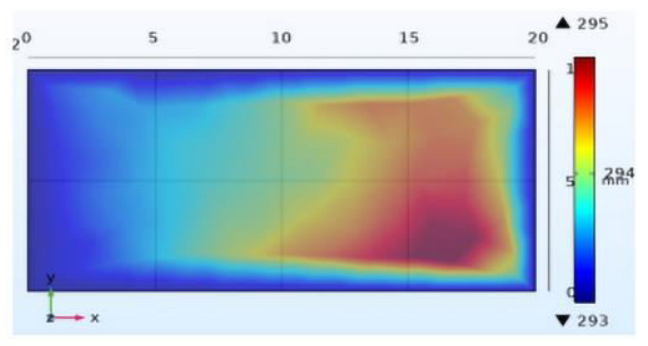

(c) $v=67 \mathrm{~m} / \mathrm{s}$

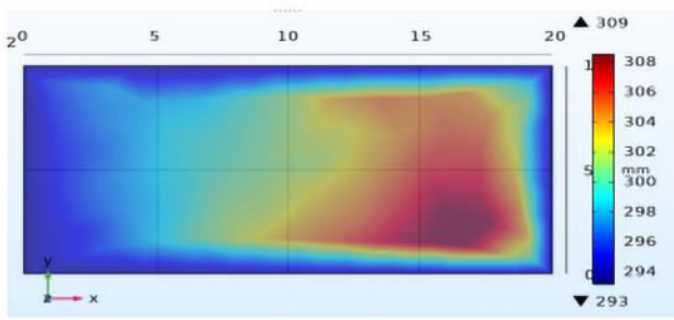

(b) $v=15 \mathrm{~m} / \mathrm{s}$

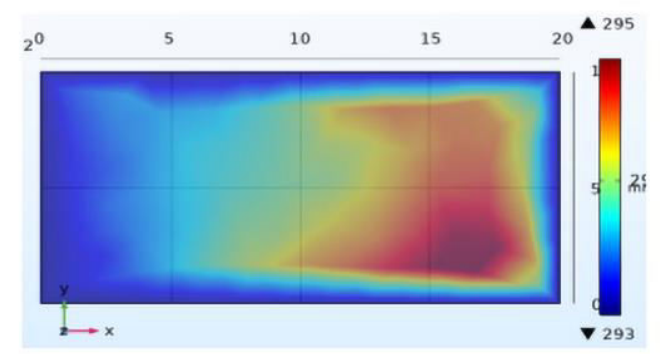

(d) $v=70 \mathrm{~m} / \mathrm{s}$

Fig. 15 Distribution of temperature domain in gap at different flow rates

When the magnetic field line is parallel to the electric field line and the flow field line is perpendicular, it can be seen from figure 15 that the magnetic field will affect the temperature field between the inlet velocity $0-67 \mathrm{~m} / \mathrm{s}$, and the inlet velocity greater than $67 \mathrm{~m} / \mathrm{s}$, will no longer affect the temperature field

\section{2) Flow field distribution}

When the magnetic field line is parallel to the electric field line and the flow field line is perpendicular, the initial temperature increases obviously, and the bottom decreases with the addition temperature of the flow rate, as shown in figure 16.

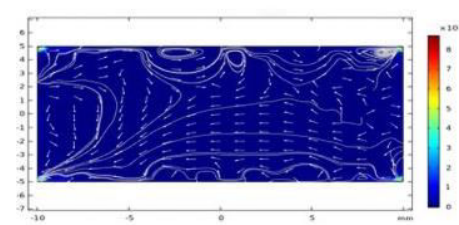

(a) $v=0 \mathrm{~m} / \mathrm{s}$

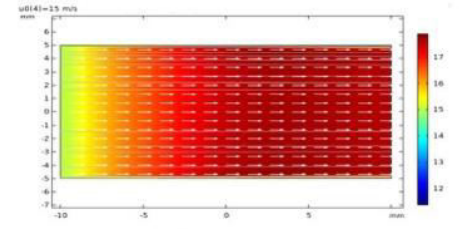

(b) $v=15 \mathrm{~m} / \mathrm{s}$

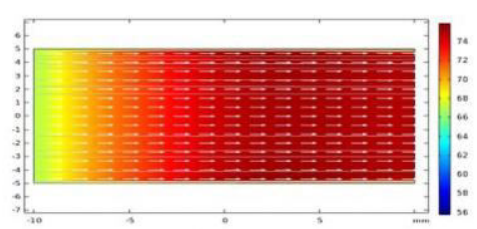

(c) $v=67 \mathrm{~m} / \mathrm{s}$

Fig. 16 Flow field distribution in gap at different inlet velocity

From figure 16, it is known that when the magnetic field line is perpendicular to the flow field, it hinders the flow field. According to the energy conservation of the fluid, the electromagnetic force is weaker than the lower two sides, so the velocity above is larger than the velocity below. Because of the upward direction of electromagnetic force, the velocity of flow at the upper right of the outlet of the hydrostatic fluid varies greatly, and the velocity of flow at the lower right is relatively small. However, with the increase of velocity, the hindrance of electromagnetic force is relatively small. When the velocity reaches $15 \mathrm{~m} / \mathrm{s}$, the magnetic field has little effect on the velocity of flow. 


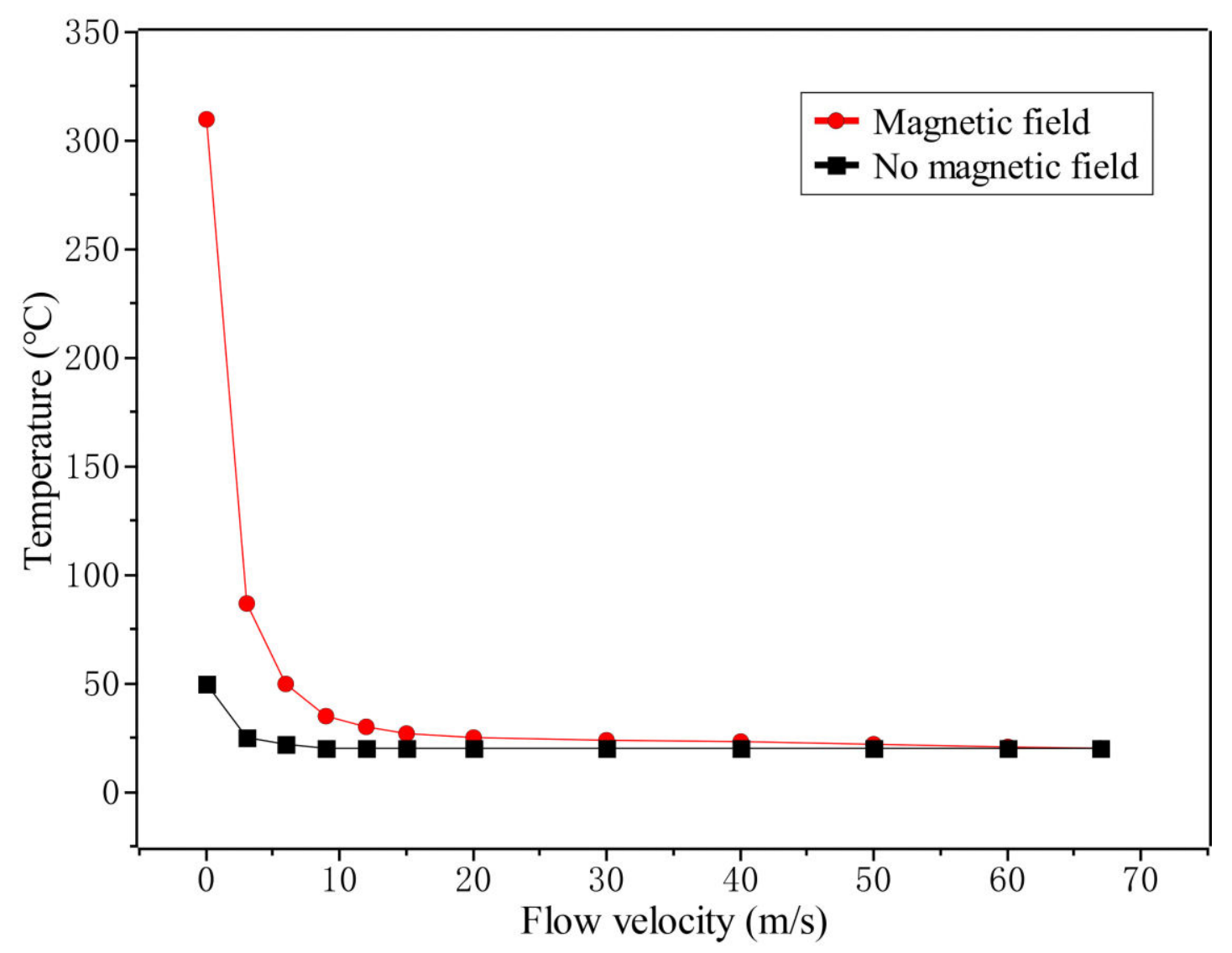

Fig. 17 Comparison of the distribution of temperature regions at different velocity of magnetic field and magnetic field

When the magnetic field line is parallel to the electric field line and the flow field line is perpendicular, the initial temperature of the static liquid is higher, and the temperature begins to decrease with the addition of the flow rate. From figure 17 above, we can see that when the magnetic field is parallel to the electric field line and the flow field is perpendicular to the flow field, the temperature reaches a constant temperature when the flow rate reaches $67 \mathrm{~m} / \mathrm{s}$ and does not change, and the temperature also increases obviously when the magnetic field is not added. However, the effect of the magnetic field addition on the flow field is relatively weak.

2.4 The magnetic field is added and the magnetic field line is perpendicular to the electric field line and the flow field line

1) Distribution of temperature domain at different velocity of flow

The magnetic field distribution is shown in Figure 18. 


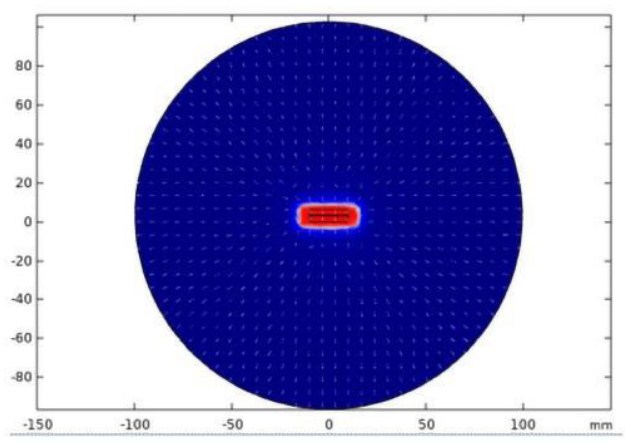

(a) Two-dimensional model

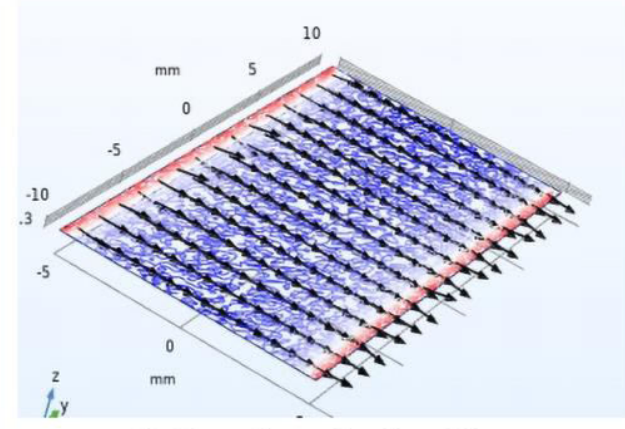

(b) Three-dimensional model

Fig.18 Three-dimensional model of magnetic field line parallel to electric field and perpendicular to flow field

After adding magnetic field to the turbulence model, the simulation model of temperature range under different velocity is carried out. The final simulation results are as follows:

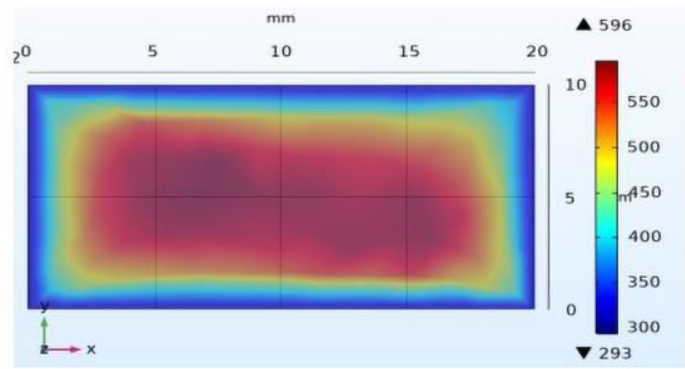

(a) $v=0 \mathrm{~m} / \mathrm{s}$

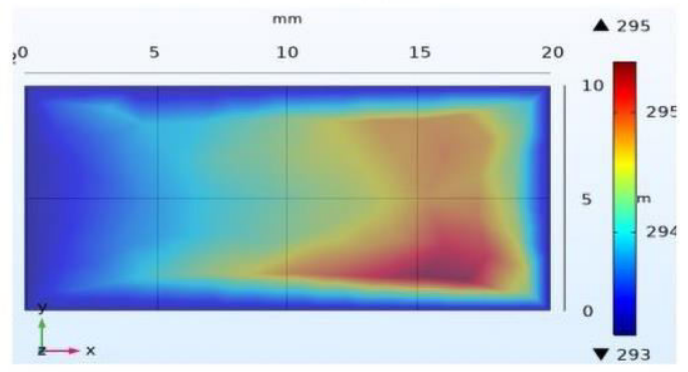

(c) $v=86 \mathrm{~m} / \mathrm{s}$

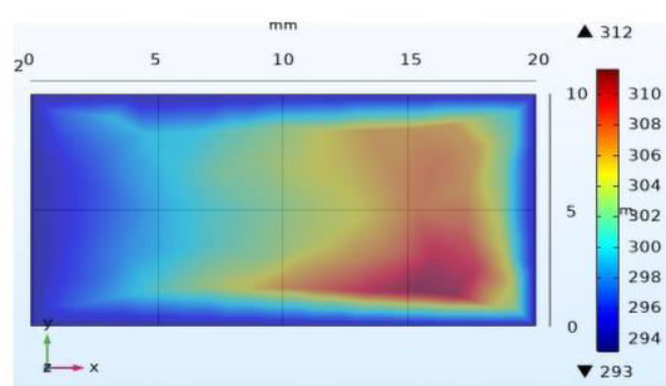

(b) $v=15 \mathrm{~m} / \mathrm{s}$

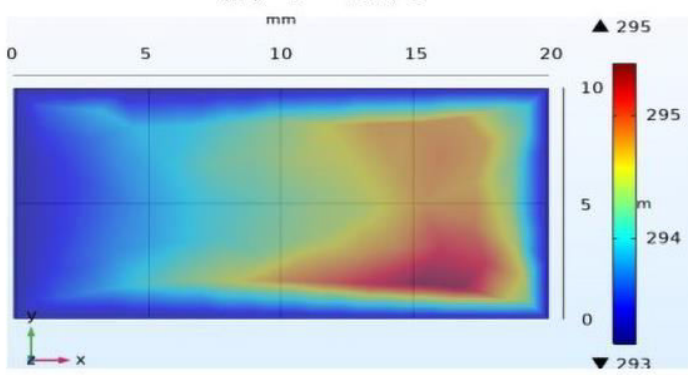

(d) $v=90 \mathrm{~m} / \mathrm{s}$

Fig. 19 Distribution of temperature domain in gap at different flow rates

The above figure 19 shows that when the magnetic field line, electric field and flow field are perpendicular, the maximum temperature of the static liquid is $295^{\circ} \mathrm{C}$, the velocity of flow increases and the temperature decreases. When the inlet velocity is $15 \mathrm{~m} / \mathrm{s}$, the temperature is $37^{\circ} \mathrm{C}$, until the inlet velocity is $86 \mathrm{~m} / \mathrm{s}$, the temperature no longer changes and reaches the constant temperature.

\section{2) Flow field distribution in gap different inlet velocity}

When the magnetic field line, the electric field line and the flow field line are perpendicular, as shown in figure 20, the comparison diagram of the temperature 
domain at different flow rates when the magnetic field is added and the magnetic field is not.

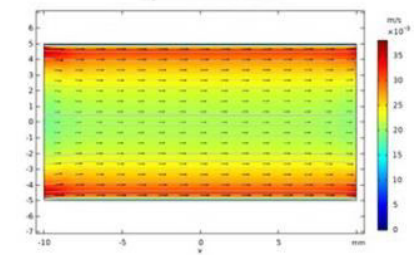

(a) $v=0 \mathrm{~m} / \mathrm{s}$

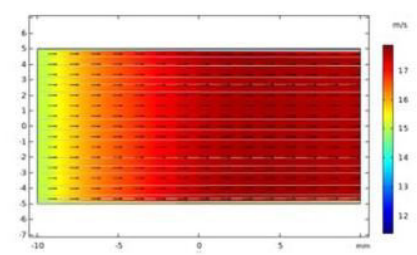

(b) $v=15 \mathrm{~m} / \mathrm{s}$

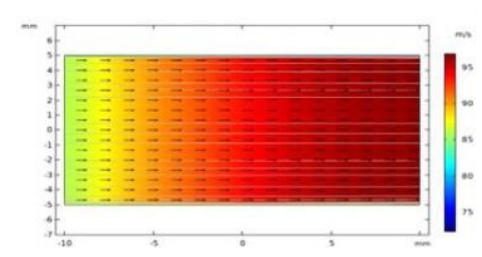

(c) $v=86 \mathrm{~m} / \mathrm{s}$

Fig. 20 Flow field distribution in gap at different inlet velocity

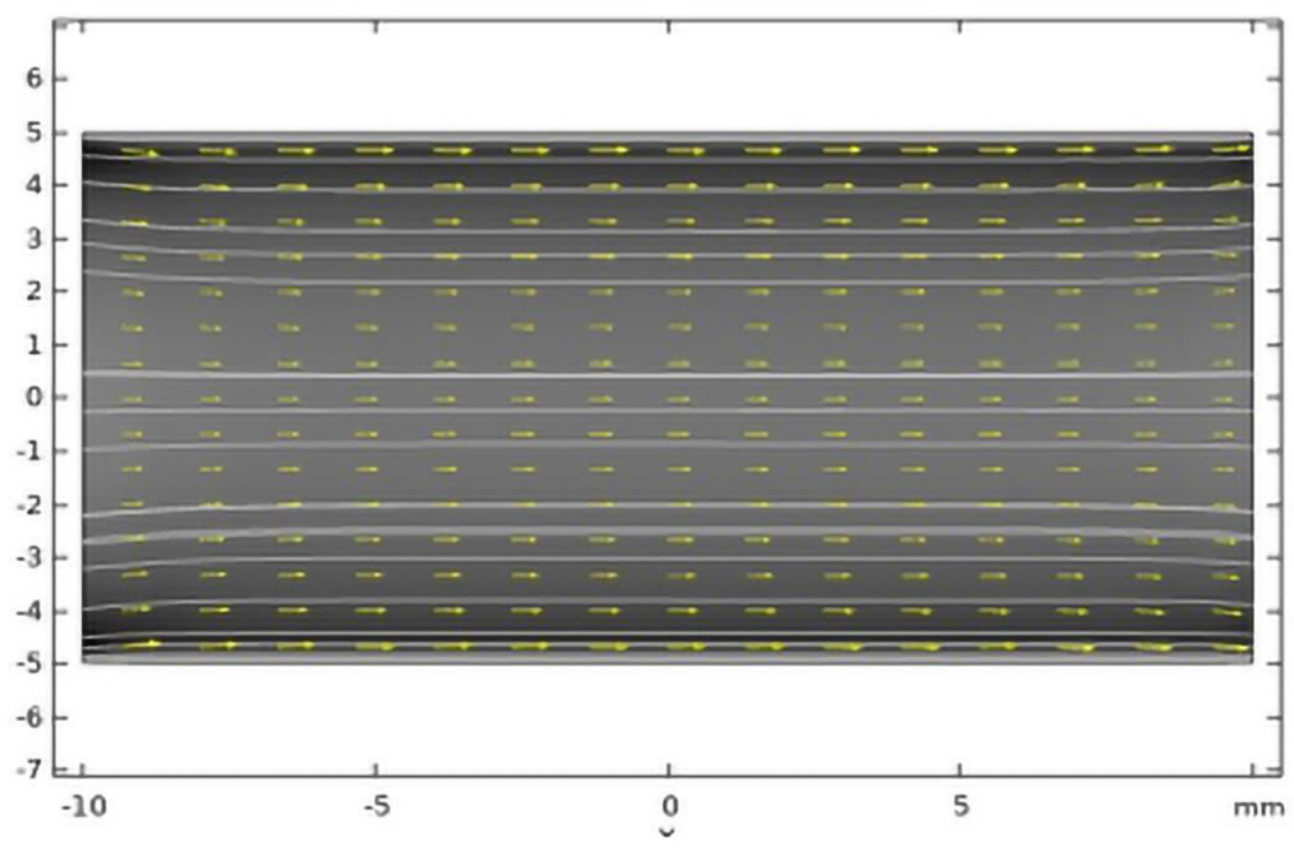

Fig. 21 The Distribution of magnetic force

It is known from figure 21 that when the electrolyte is still liquid, the velocity of flow in the upper and lower sides of the gap is relatively large and the intermediate velocity is small. According to the conservation of fluid energy, the magnetic field is relatively large in the middle of the flow field under this electromagnetic force distribution (Figure. 18). However, with the increase of inlet velocity, the influence of magnetic field on the flow field will be very weak until it has almost no effect. 


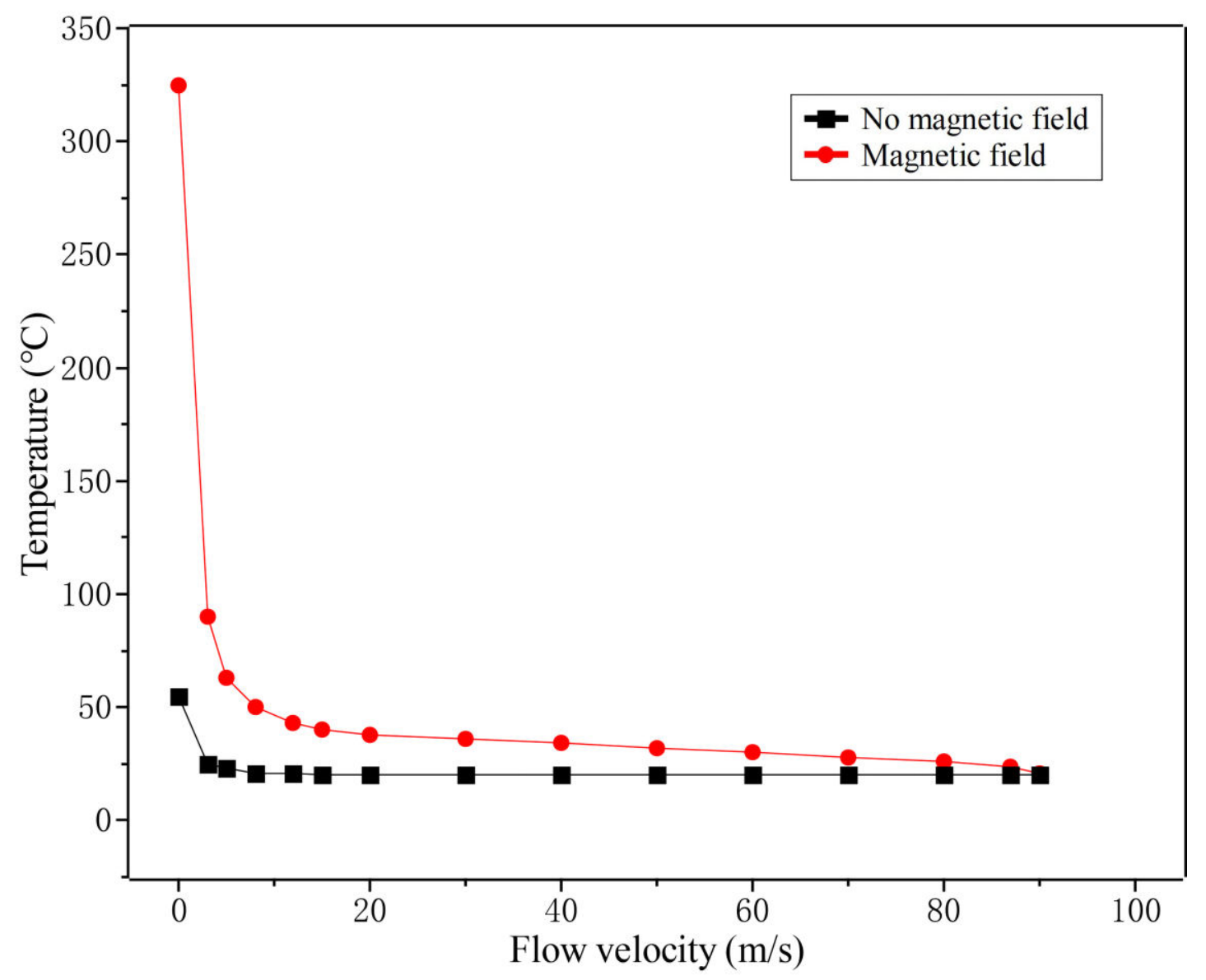

Fig. 22 Comparison of the distribution of temperature regions at different velocity of magnetic and non-magnetic

According to figure 22 above, when the flow rate reaches $86 \mathrm{~m} / \mathrm{s}$, the temperature reaches constant temperature, and the electromagnetic force in the horizontal direction drives the electrolyte flow. If the electrolyte forms a beam in the process of electrolysis, the addition of magnetic field can expand the beam, avoid holes and eddy currents, and improve the distribution of electrolytic flow field.

\section{The Relationship between temperature and voltage model}

\subsection{Simulation Analysis of Current Density without Magnetic Field}

During the traditional electrolysis process, the electrolyte flow rate is usually 5 $\mathrm{m} / \mathrm{s}, 10 \mathrm{~m} / \mathrm{s}, 15 \mathrm{~m} / \mathrm{s}, 20 \mathrm{~m} / \mathrm{s}$. And the current density of the four flow rates is simulated. The results are shown in figure 23: 


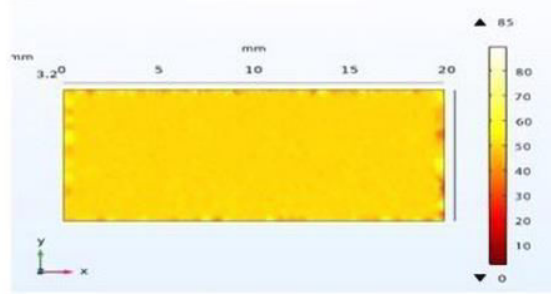

(a) $v=5 \mathrm{~m} / \mathrm{s}$

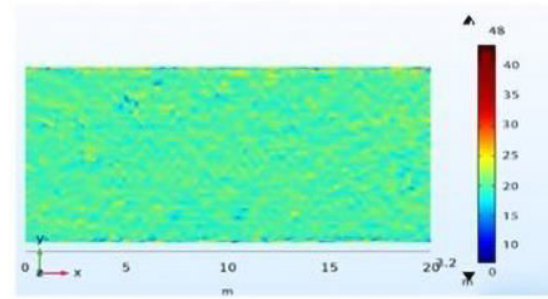

(c) $v=15 \mathrm{~m} / \mathrm{s}$

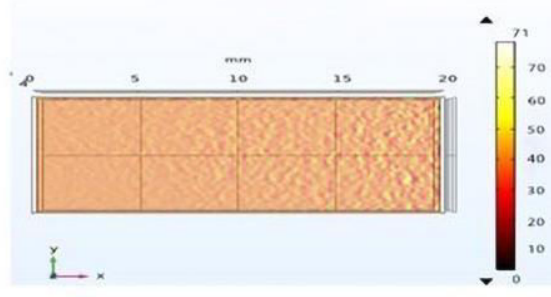

(b) $v=10 \mathrm{~m} / \mathrm{s}$

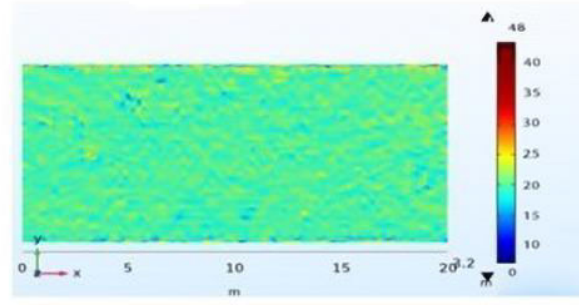

(d) $v=20 \mathrm{~m} / \mathrm{s}$

Fig. 23 Distribution of current density at different inlet velocity without magnetic field

The current density decreases with the increase of flow rate. When the flow rate is $5 \mathrm{~m} / \mathrm{s}$, the temperature is relatively high and the current density is $85 \mathrm{~A} / \mathrm{m}$. Figure 23 shows that the flow rate increases to $15 \mathrm{~m} / \mathrm{s}$, the current density reaches $48 \mathrm{~A} / \mathrm{m}^{2}$ but the current density does not change when the flow rate is added to $20 \mathrm{~m} / \mathrm{s}$. Since the temperature is constant when the flow rate reaches $15 \mathrm{~m} / \mathrm{s}$, the temperature remains unchanged when the flow rate is $20 \mathrm{~m} / \mathrm{s}$. It can be obtained that the increase and decrease of temperature affect the increase or decrease of current density.

3.2 When a magnetic field is added and the magnetic field line is perpendicular to the electric field and parallel to the flow field line

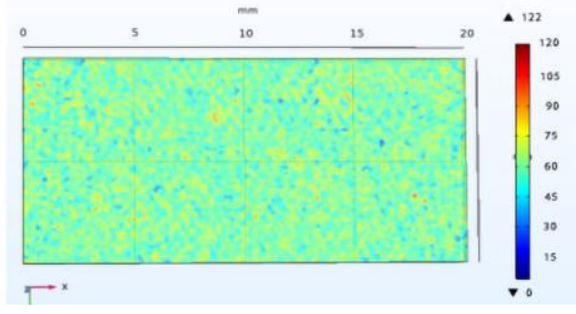

(a) $v=5 \mathrm{~m} / \mathrm{s}$

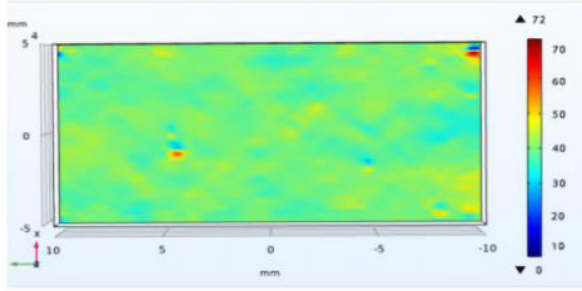

(c) $v=15 \mathrm{~m} / \mathrm{s}$

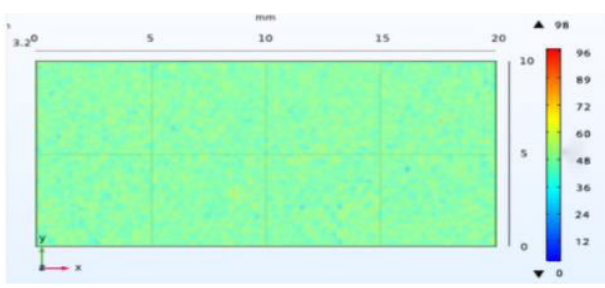

(b) $v=10 \mathrm{~m} / \mathrm{s}$

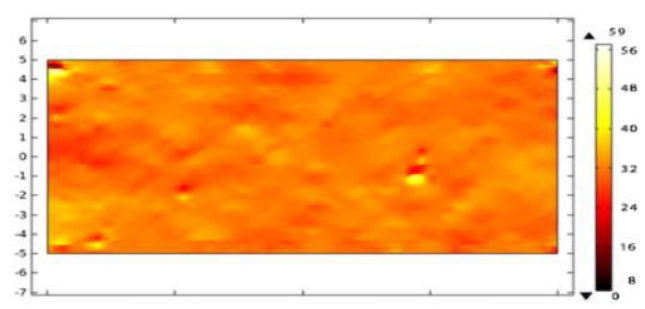

(d) $v=20 \mathrm{~m} / \mathrm{s}$

Fig. 24 Distribution of current density at different temperatures when the magnetic field line 
is perpendicular to the electric field and parallel to the flow field line

As shown in figure 24, the current density increases with the increase of temperature after adding magnetic field. When the flow rate is $5 \mathrm{~m} / \mathrm{s}$, the current density reaches $122 \mathrm{~A} / \mathrm{m}$, the temperature of the electrolyte increases, the current density increases, while the current density used for metal dissolution accounts for more than when the magnetic field is not added, and its amplitude increases with the change of temperature.

3.3 The magnetic field is added and the magnetic field line is parallel to the electric field and the flow field line is perpendicular

The simulation of the current density at the inlet velocity of $5 \mathrm{~m} / \mathrm{s}, 10 \mathrm{~m} / \mathrm{s}, 15 \mathrm{~m} / \mathrm{s}$ and $20 \mathrm{~m} / \mathrm{s}$.

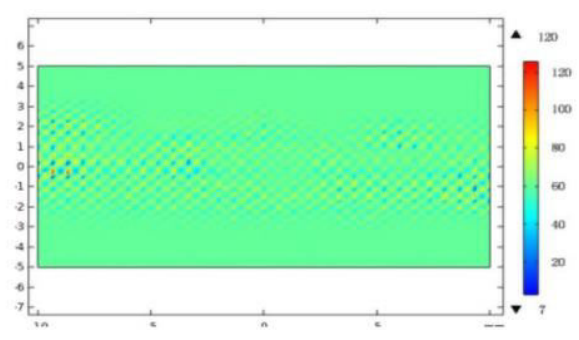

(a) $v=5 \mathrm{~m} / \mathrm{s}$

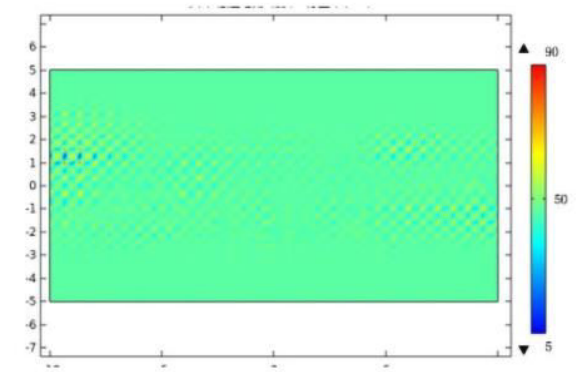

(c) $v=15 \mathrm{~m} / \mathrm{s}$

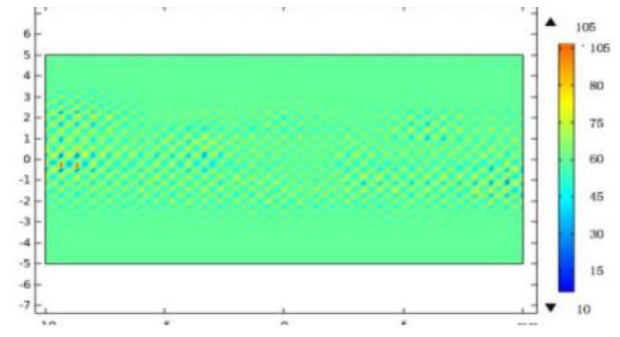

(b) $v=10 \mathrm{~m} / \mathrm{s}$

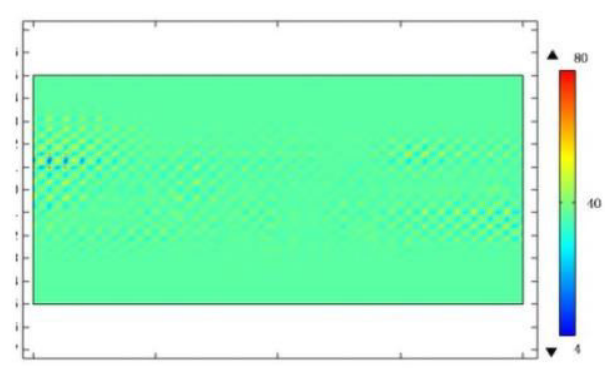

(d) $v=20 \mathrm{~m} / \mathrm{s}$

Fig. 25 Distribution of current density at different temperatures where the magnetic field line is parallel to the electric field and perpendicular to the flow field line

Figure 25 shows that the current density increases greatly with the increase of temperature after adding magnetic field. The current density distribution is concentrated because of the volume force. When the flow rate is up to $5 \mathrm{~m} / \mathrm{s}$, the current density reaches $120 \mathrm{~A} / \mathrm{m}$. The current density will be reduced due to the increase of the flow rate and the decrease of the temperature of a large amount of thermoelectric solutions in the gap.

3.4 When a magnetic field is added and the magnetic field line is perpendicular to the electric field, the flow field line is perpendicular

The simulation of current density is also carried out by selecting the same inlet flow velocity as that without adding magnetic field, such as Figure 26 shows. 


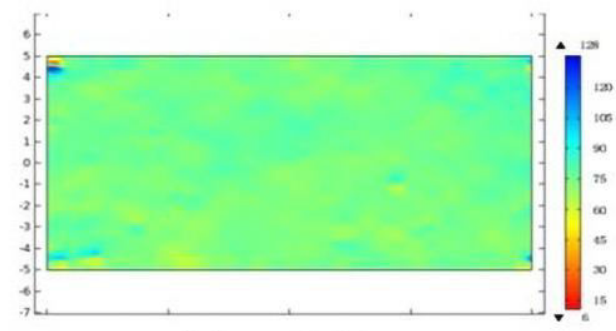

(a) $v=5 \mathrm{~m} / \mathrm{s}$

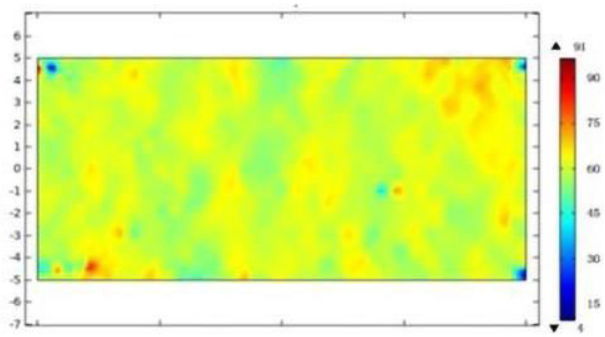

(c) $v=15 \mathrm{~m} / \mathrm{s}$

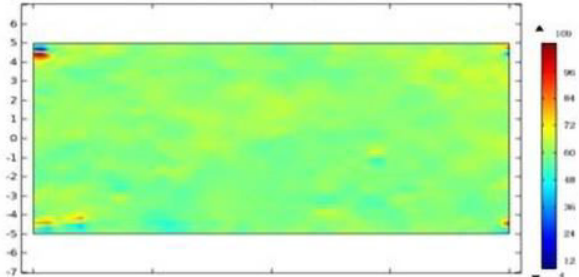

(b) $v=10 \mathrm{~m} / \mathrm{s}$

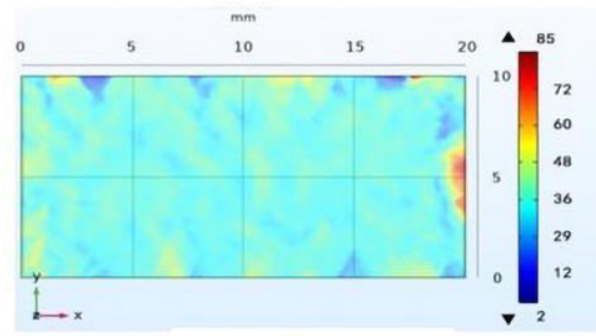

(d) $v=20 \mathrm{~m} / \mathrm{s}$

Fig. 26 Distribution of current density at different temperatures when the magnetic field line is perpendicular to the electric field

From figure 26, we can see that the increase of current density is caused by the addition of magnetic field and the increase of temperature. The current density distribution is concentrated because of the volume force. When the flow rate is up to 5 $\mathrm{m} / \mathrm{s}$, the current density reaches $128 \mathrm{~A} / \mathrm{m}$.12The increase of flow velocity decreases the temperature of a large amount of pyrolytic fluid in the gap and the current density decreases. The current density distribution of $5 \mathrm{~m} / \mathrm{s}, 10 \mathrm{~m} / \mathrm{s}, 15 \mathrm{~m} / \mathrm{s}$ and $20 \mathrm{~m} / \mathrm{s}$ under the above three different magnetic fields is simulated. The streamline figure 27 is as follows: 


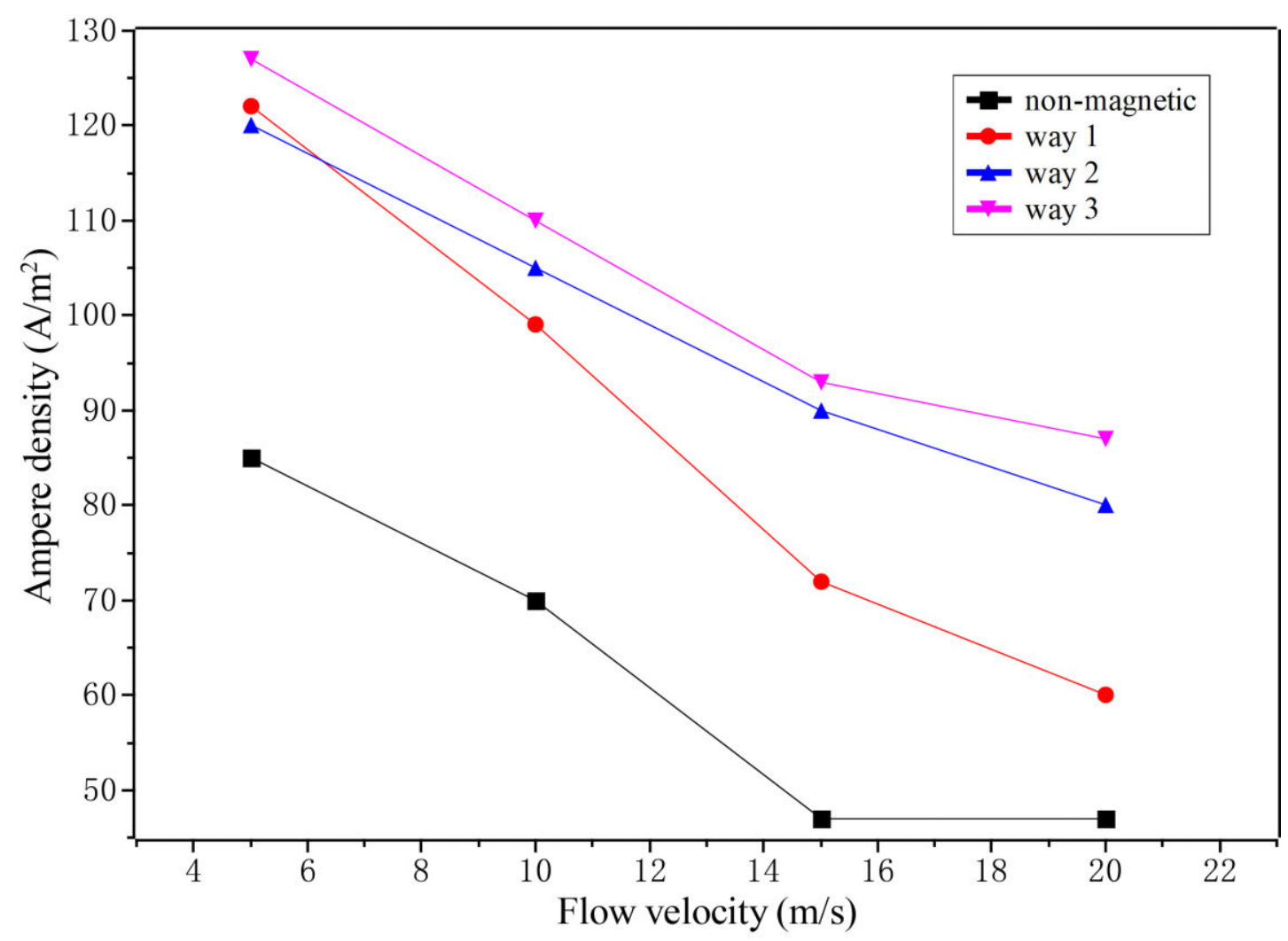

Fig. 27 Distribution of current density in a certain inlet velocity gap under different magnetic fields

The conductivity of the electrolyte is closely related to the final forming of the workpiece, and the conductivity and temperature can be used Expressionsk $=\mathrm{k}_{0}(1+$ $\left.\mathrm{a}\left(\mathrm{T}-\mathrm{T}_{0}\right)\right)$. The data sheet is as follows Tab.2.

Table 2 Current density at different magnetic field placement and inlet velocity

\begin{tabular}{ccccc}
\hline $\begin{array}{c}\text { Flow Rate The } \\
\text { Current Density } \\
\text { Magnetic Field }\end{array}$ & Non-magnetic & Type-1 & Type-2 & Type-3 \\
\hline 5 & 85 & 122 & 120 & 128 \\
10 & 71 & 98 & 105 & 109 \\
15 & 48 & 72 & 90 & 91 \\
20 & 48 & 59 & 80 & 85 \\
\hline
\end{tabular}

Because of the addition of magnetic field, the effect of Loren magnetic force on the ion becomes regular distribution, so the distribution of current density is more neat than that of magnetic field. And when the temperature does not change, the current density is constant.

3.5 Relationship between temperature and voltage model with vertical magnetic field assistance

The relationship between magnetic field, electric field, temperature field and 
flow field in electrolytic processing is affected by each other.

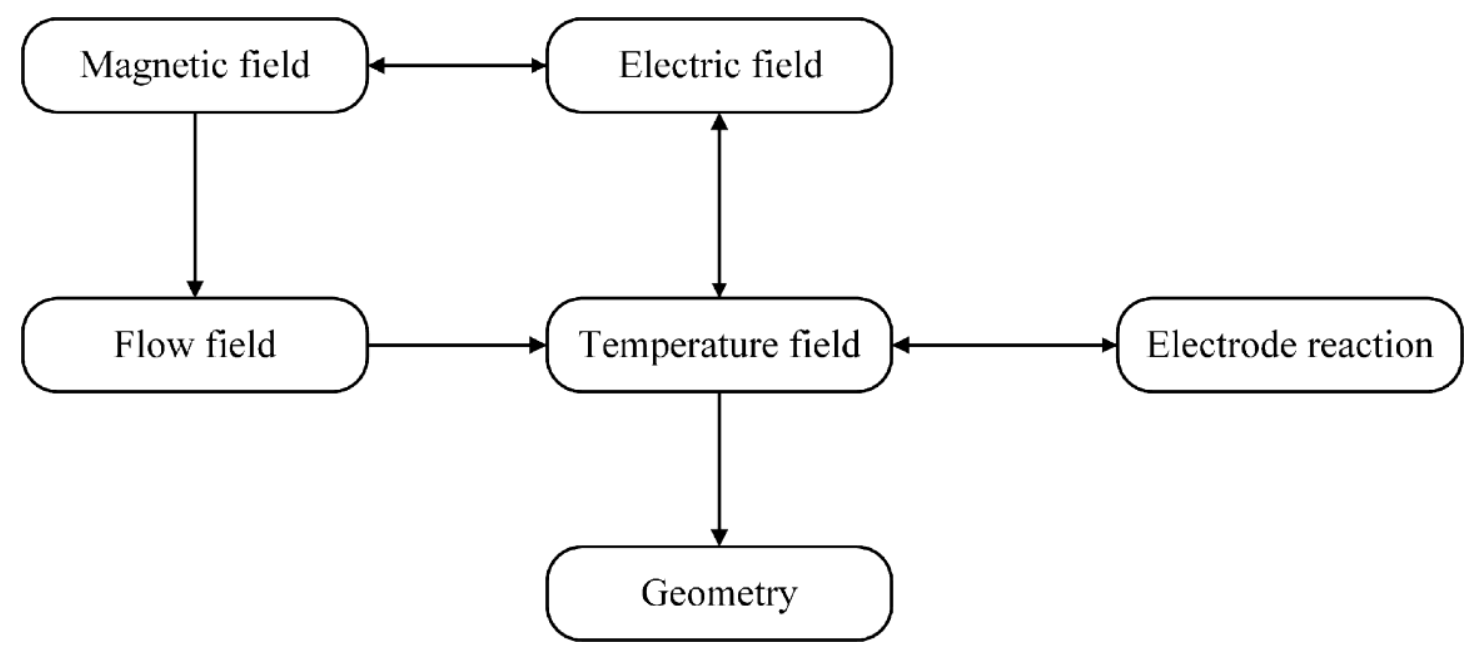

Fig.28 Effects of physical fields

When the machining gap is $0.5 \mathrm{~mm}$, the magnetic field intensity is $0.5 \mathrm{~T}$, the magnetic field placement mode is perpendicular to the magnetic field line, the electric field and the flow field line. When the machining voltage is $5 \mathrm{v}, 10 \mathrm{v}, 20 \mathrm{v}$, the distribution of the temperature domain in the gap under different inlet velocity (5 $\mathrm{m} / \mathrm{s}, 10 \mathrm{~m} / \mathrm{s}, 15 \mathrm{~m} / \mathrm{s}, 20 \mathrm{~m} / \mathrm{s}$ ) is simulated. Its streamline figure 29 is as follows:

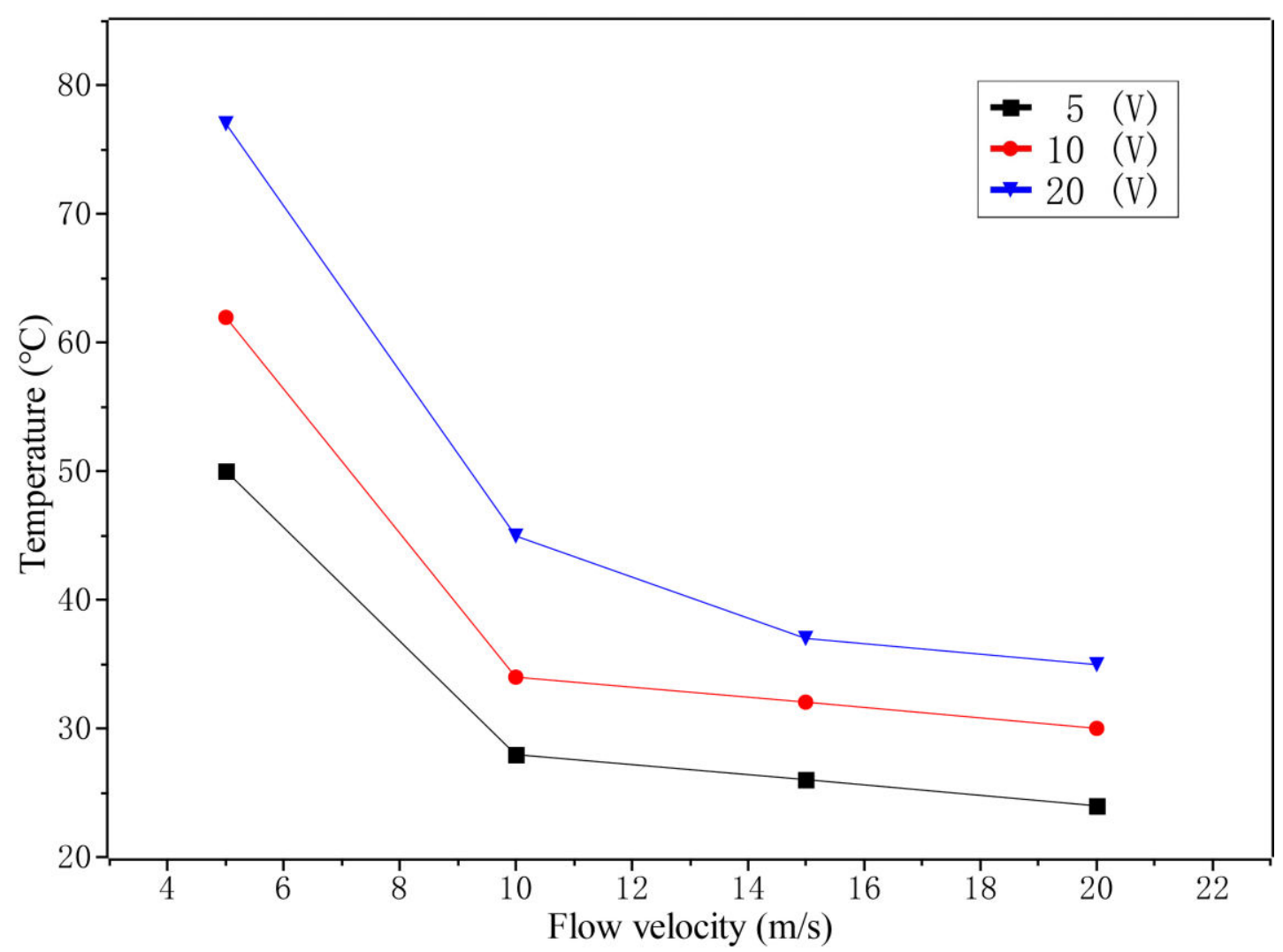

Fig .29 Simulation of temperature field distribution in gap at different inlet velocity 
Figure 29 shows that the inlet velocity is small, the temperature is relatively high, and the temperature decreases gradually with the increase of the flow rate. When the flow rate is $5 \mathrm{~m} / \mathrm{s}$, the temperature difference is $27^{\circ} \mathrm{C}$ when the voltage is $20 \mathrm{~V}$.

\subsection{Relationship between machining clearance and temperature under vertical magnetic field assistance}

Electrolytic machining clearance has an important effect on the surface forming accuracy of the workpiece. The distribution streamline diagram 4-9 of the temperature domain when the machining gap is $0.1 \mathrm{~mm}, 0.2 \mathrm{~mm}, 0.3 \mathrm{~mm}$ and $0.5 \mathrm{~mm}$, and the corresponding inlet velocity is $5 \mathrm{~m} / \mathrm{s}, 10 \mathrm{~m} / \mathrm{s}, 15 \mathrm{~m} / \mathrm{s}$ and $20 \mathrm{~m} / \mathrm{s}$ respectively:

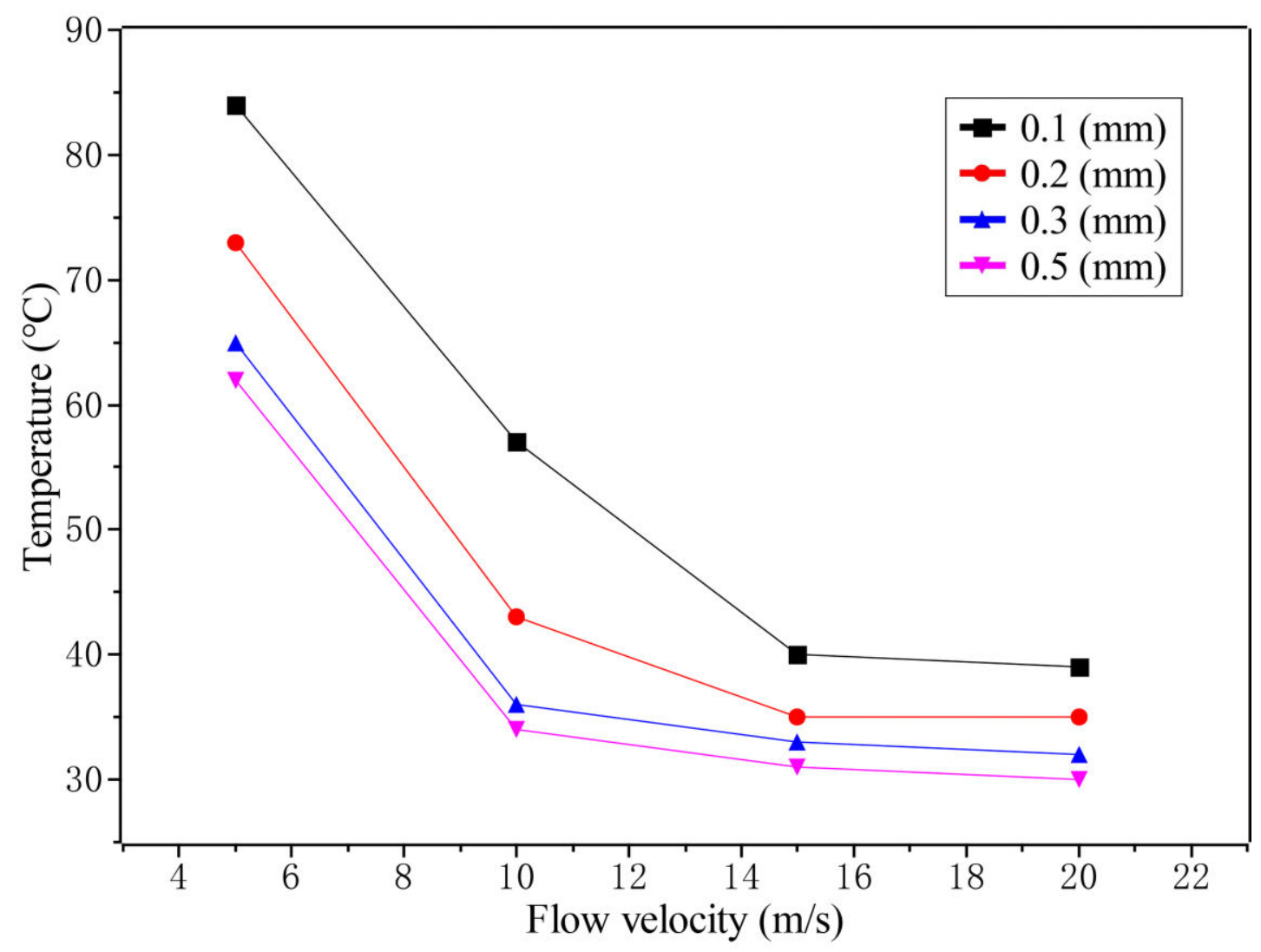

Fig .30 Temperature domains in different gaps at different inlet velocity of vertical magnetic field

As shown in figure 30, when the gap must be, increasing the electrolyte flow rate takes away the reaction heat in the gap and the temperature decreases. When the flow rate reaches $20 \mathrm{~m} / \mathrm{s}$, the temperature in the gap does not change. At the same electrolyte flow rate, the larger the gap, the lower the reaction heat of the electrolyte. When the flow rate of electrolyte is $5 \mathrm{~m} / \mathrm{s}$, the temperature reaches $84^{\circ} \mathrm{C}$, and the electrolyte may lead to hole phenomenon, which seriously affects the accuracy of machining parts.

If the machining gap is $0.1 \mathrm{~mm}$, the electrolyte flow rate is faster than other gaps, but the temperature in the time gap is also the highest, so the selection of machining gap is very important. However, too high temperature in the gap will also affect the surface accuracy of the workpiece. 


\subsection{Conclusions}

In this paper, the principle of magnetic field assisted electrolytic processing and multi-physical field coupling is analyzed, and the relationship between magnetic field, electric field, flow field and temperature field in the process of electrolytic processing is revealed. The following conclusions are obtained:

(1) When the magnetic field is perpendicular to the electric field and the flow field is parallel. When the inlet velocity is $0-40 \mathrm{~m} / \mathrm{s}$, the magnetic field will have an effect on the magnetic field. When the inlet velocity is more than $40 \mathrm{~m} / \mathrm{s}$, the magnetic field will have an effect on the temperature field between $0-67 \mathrm{~m} / \mathrm{s}$ and the inlet velocity is more than $67 \mathrm{~m} / \mathrm{s}$. When the inlet velocity is vertical, the magnetic field will have an effect on the temperature field between $0-86 \mathrm{~m} / \mathrm{s}$ and the inlet velocity is more than $86 \mathrm{~m} / \mathrm{s}$.

(2) The magnetic field affects the electric field and the flow field. The magnetic field combines with the electric field to form an electromagnetic force. The anode ion accelerates the removal of the workpiece under the action of the electromagnetic field. The electric field produces a large amount of Joule heat.

(3) In a vertical magnetic field, the voltage affects the variation of the temperature domain in the gap. That is, the increase of voltage leads to the increase of electrolyte temperature, but the temperature will decrease with the increase of electrolyte flow rate.

(4) In the vertical magnetic field, the temperature of the electrolyte in the gap increases with the decrease of the gap, but with the decrease of the gap, the flow rate of the electrolyte accelerates and takes away more joule heat. 


\section{References}

[1] Huang L, Cao Y, Tian C, Zhao R, Wang Y (2021) Key technology of the electrochemical machining flow field in aero-rotor blades made of inconel718. Electrochemistry Tokyo

[2] Kozak, J (2019) Quasi-homogenous model of electrochemical machining of turbine engine parts. Journal of KONES, 26(3), 91-104

[3] Liu W D, Ao S S, Li Y, et al (2017). Elimination of the over cut from a repaired turbine blade tip post-machined by electrochemical machining. J Journal of Materials Processing Technology 231: $27-37$

[4] Kozhina TD, Kurochkin, AV (2016) Results of investigative tests of gas turbine engine compressor blades obtained by electrochemical machining. C IOP Conference 127, 012044

[5] Lin T, Weimin G, Zhijian F, et al (2014) Gun Tube Rifling Electrochemical Machining Cathode Design and Experiment Study

[6] Hasanpour R, Rostami J, Thewes M, et al (2018) Parametric study of the impacts of various geological and machine parameters on thrust force requirements for operating a single shield TBM in squeezing ground. J Tunnelling and Underground Space Technology 73:252-260

[7] Sun J, Zhou Y, Deng J, et al (2016) Effect of hybrid texture combining micro-pits and micro-grooves on cutting performance of WC/Co-based tools. J International Journal of Advanced Manufacturing Technology 86:9-12

[8] Hu Y (2014) Study on Pressure Control of Electrolyte in Complex Surface Electrolysis. D Nanjing University of Aeronautics and Astronautics.

[9] Wang F, Xu J ,Zhao J, et al (2006) A Method of Selecting Electrochemical Machining Parameters Based on Numerical Simulation of Electrochemical Machining Process. J China Mechanical Engineering 17(7):716-715

[10] Elhami S, Razfar, MR (2020) Numerical and experimental study of discharge mechanism in the electrochemical discharge machining process. J Journal of Manufacturing Processes 50, 192-203

[11] Das PP, Chakraborty S (2020) Parametric Optimization of Electrochemical Machining Process Using Taguchi Method and Super Ranking Concept While Machining on Inconel 825. M Advanced Engineering Optimization Through Intelligent Techniques. Springer, Singapore $407-415$

[12]Loebel S, Zinecker M, Steinert P, Schubert A (2021) Transient simulation of electrochemical machining processes for manufacturing of surface structures in high-strength materials. J Engineering Reports e12360

[13] Paul R, Hackert-Oschtzchen M, Danilov I, Zanjani MY, Schubert A(2019) 3D Multiphysics Simulation of Jet Electrochemical Machining of Intersecting Line Removals. J Procedia CIRP 82: 196-201

[14] Yang F, Zhang J, Zhao S (2020) Investigation of electrochemical machining for gradual change special-shaped deep spiral hole based on COMSOL. J The International Journal of Advanced Manufacturing Technology 108(9): 2717-2725

[15] Klocke F, Harst S, Zeis M, et al (2018) Modeling and simulation of the microstructure evolution of 42crmo4 steel during electrochemical machining. J Procedia CIRP 68, 505-510

[16] Liu G, Tong H, Li Y, et al (2020) Multiphysics research on electrochemical machining of micro holes with internal features. $\mathrm{J}$ The International Journal of Advanced Manufacturing Technology 110(5): 1527-1542 
[17] XiaoChao Z, ChangYong C, HongXin W, et al (2020) Study on the multi-field coupling model of electrolyte temperature distribution in electrochemical machining. J The International Journal of Advanced Manufacturing Technology 109(5): 1655-1662

[18] Fang M, Sun T S, Su Y S, et al (2019) Multi-physics Simulation of Heat Transfer in Pulse Electrochemical Machining (PECM) Process. C IOP Conference Series Materials Science and Engineering 592, 012079

[19] Hu X, Zhu D, Li J, et al (2019) Flow field research on electrochemical machining with gas film insulation. J Journal of Materials Processing Technology 267: 247-256

[20] Zhu Z, Wang D, Bao J, et al (2015) Process simulation of electrochemical machining of convexity structure on revolving workpiece. C International Manufacturing Science and Engineering Conference. American Society of Mechanical Engineers 56826: V001T02A044

[21] Li J, Wang D, Zhu D, et al (2020) Analysis of the flow field in counter-rotating electrochemical machining. J Journal of Materials Processing Technology 275: 116323

[22] Volgin VM, Lyubimov VV, Davydov AD (2015) Modeling and numerical simulation of electrochemical micromachining. J Chemical Engineering Science 140: 252-260

[23] Li Z, Zhu D (2005) Design of cathode for blade electrolysis based on gap conductivity model. J Journal of South China University of Technology (Natural Science Edition) 03:73-77

[24] Chen Y, Fang M, Pei D, Chang W (2016) Multi-field Coupling Simulation for Electrochemical Machining of Blade. J China Mechanical Engineering 27(22):3087-3092

[25] Li Q (2014) Analysis of COMSOL Flow Field in Electrolytic Machining of External Flow Channel of Closed Integral Component Xi'an University of Technology

[26] Qiu G (2018) Evolution of Dynamic Forming and Experimental Study on Micro Electrolytic Machining Materials with Gas Film Shielding . D Zhejiang University of Technology

[27] Ning S, Wang R, Ma B (2015) Simulation Analysis of the effect of Magnetic Field on interstitial flow Field in Electrolytic Machining. J Mechanical Design and Manufacturing 08:89-93 